\title{
FBXW7: a critical tumor suppressor of human cancers
}

\author{
Chien-Hung Yeh ${ }^{\dagger}$, Marcia Bellon ${ }^{\dagger}$ and Christophe Nicot ${ }^{*}$ (D)
}

\begin{abstract}
The ubiquitin-proteasome system (UPS) is involved in multiple aspects of cellular processes, such as cell cycle progression, cellular differentiation, and survival (Davis RJ et al., Cancer Cell 26:455-64, 2014; Skaar JR et al., Nat Rev Drug Discov 13: 889-903, 2014; Nakayama Kl and Nakayama K, Nat Rev Cancer 6:369-81, 2006). F-box and WD repeat domain containing 7 (FBXW7), also known as Sel10, hCDC4 or hAgo, is a member of the F-box protein family, which functions as the substrate recognition component of the SCF E3 ubiquitin ligase. FBXW7 is a critical tumor suppressor and one of the most commonly deregulated ubiquitin-proteasome system proteins in human cancer. FBXW7 controls proteasome-mediated degradation of oncoproteins such as cyclin E, c-Myc, Mcl-1, mTOR, Jun, Notch and AURKA. Consistent with the tumor suppressor role of FBXW7, it is located at chromosome 4q32, a genomic region deleted in more than $30 \%$ of all human cancers (Spruck CH et al., Cancer Res 62:4535-9, 2002). Genetic profiles of human cancers based on high-throughput sequencing have revealed that FBXW7 is frequently mutated in human cancers. In addition to genetic mutations, other mechanisms involving microRNA, long non-coding RNA, and specific oncogenic signaling pathways can inactivate FBXW7 functions in cancer cells. In the following sections, we will discuss the regulation of FBXW7, its role in oncogenesis, and the clinical implications and prognostic value of loss of function of FBXW7 in human cancers.
\end{abstract}

Keywords: FBXW7, CDC4, Cancer, C-myc, Cyclin E, mcl-1, Notch, HTLV, mTOR, Jun

\section{FBXW7 oncogenic substrates and its role as a tumor suppressor in cancer}

FBXW7 is a member of the F-box protein family, which is part of the Skp1-Cdc53/Cullin-F-box-protein complex $(\mathrm{SCF} / \beta-\mathrm{TrCP})$. The SCF complex is an E3-ubiquitin ligase that ubiquinates proteins and triggers proteasome degradation. The SCF complex is composed of four subunits - Skp1, Cul-1 (Cullin/Cdc53), and Rbx1 proteins and a fourth component consisting of a variable F-box protein that determines substrate specificity. These F-box proteins, including FBXW7, are responsible for recognizing and binding to phosphorylated substrates regulating their turnover. In mammalian cells there are three FBXW7 isoforms: FBXW7 $\alpha$, FBXW7 $\beta$, and FBXW7 $\gamma$, which differ in their 5'-UTR and N-terminal coding regions. These isoforms have distinct cellular localizations restricting interactions with specific partners and their functions. FBXW7 $\alpha$ is localized in the nucleoplasm,

\footnotetext{
* Correspondence: cnicot@kumc.edu

${ }^{+}$Chien-Hung Yeh and Marcia Bellon contributed equally to this work. Department of Pathology and Laboratory Medicine, Center for Viral Pathogenesis, University of Kansas Medical Center, 3901 Rainbow Boulevard, Kansas City, KS 66160, USA
}

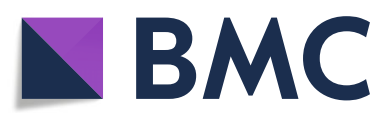

(c) The Author(s). 2018 Open Access This article is distributed under the terms of the Creative Commons Attribution 4.0 International License (http://creativecommons.org/licenses/by/4.0/), which permits unrestricted use, distribution, and reproduction in any medium, provided you give appropriate credit to the original author(s) and the source, provide a link to the Creative Commons license, and indicate if changes were made. The Creative Commons Public Domain Dedication waiver (http://creativecommons.org/publicdomain/zero/1.0/) applies to the data made available in this article, unless otherwise stated. FBXW7 $\alpha$ is ubiquitously expressed in the majority of proliferating cells and performs most of the known FBXW7 functions. All FBXW7 isoforms recognize their substrates through the presence of a conserved CDC4 phosphodegron (CPD) motif, which requires the substrate to be phosphorylated at specific residues in order to be ubiquitinated and targeted for proteasome degradation [2-4] (Fig. 1).

FBXW7 is classified as a tumor suppressor gene. FBXW7 expression increases following p53 activation, causes tumorigenesis in wild-type p53/FBXW7 mutated mice, and often demonstrates mutational and allelic loss in various human cancers [5]. Although FBXW7 -/- mice are embryonic lethal, loss of FBXW7 inhibits cell division, stem cell differentiation, enhances chromosomal instability, and can cause cancer in hematopoietic cells [6-9]. The majority of FBXW7 targets are known as proto-oncogenes, further supporting FBXW7's role as a tumor suppressor. Using FBXW7 knock-outs, it has been suggested that there may be close to 90 FBXW7 substrates [10]. The level of FBXW7-mediated degradation can be regulated two-fold 


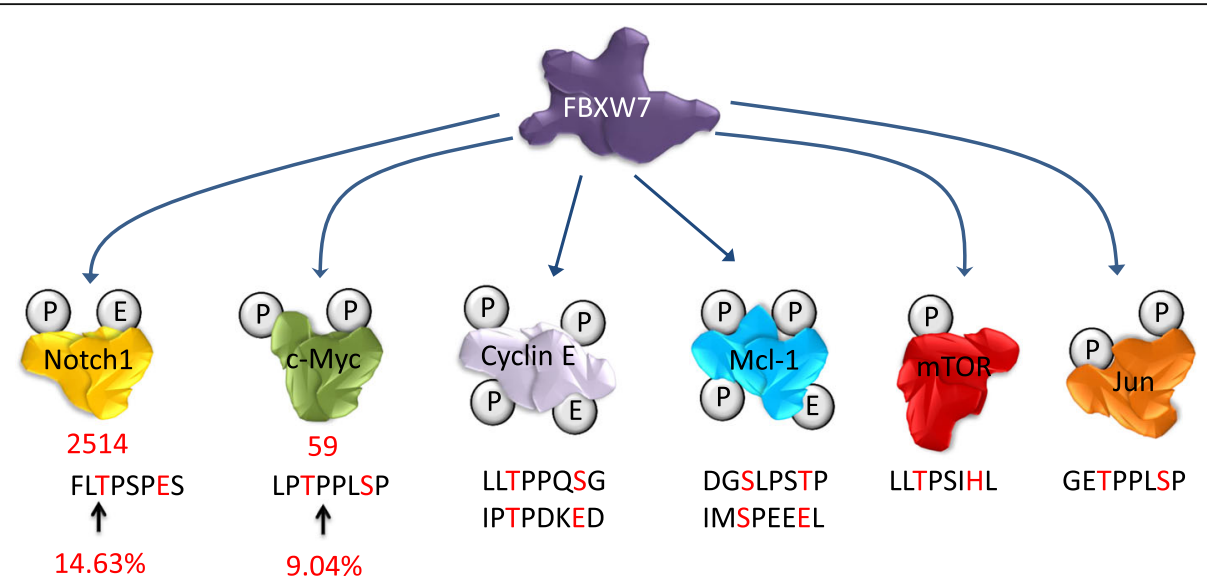

Fig. 1 FBXW7 substrates and their conserved CDC4 phosphodegron. FBXW7 causes proteasome-mediated degradation of Notch1, c-Myc, cyclin E, MCl-1, mTOR, and Jun. The amino acid sequence under each FBXW7 substrate indicates the conserved CDC4 phosphodegron (the phosphorylation residue " 0 " and "+ 4" positions are highlighted in red). The amino acid number and percentage indicate the hotspot mutations in human cancers. Mutation percentage data were retrieved from the COSMIC database

[11]. FBXW7 binding can be reinforced through multiple phosphorylation sites within the CPD motif of the substrate, allowing for additional cellular pathways to converge and regulate substrate phosphorylation/degradation. Additionally, dimerization of the FBXW7 protein itself can increase the activity and the binding of FBXW7 to substrates, especially for those substrates with weak phosphodegrons. Glycogen synthase kinase 3 beta (GSK3 $\beta$ ) is commonly recognized as a significant player in phosphorylating those substrates destined for FBXW7-mediated degradation [12]. Some of the most cancer-relevant substrates targeted by FBXW7 are discussed below (Fig. 1).

\section{c-MYC}

c-Myc is a master regulator of cellular gene transcription and is reported to bind to up to $15 \%$ of promoters in the human genome [13]. c-Myc affects cellular proliferation, survival pathways, and is frequently deregulated in human tumors [14]. Due to its central role in regulating cellular pathways, c-Myc expression and activity are tightly regulated. Among the proteins that can post-transcriptionally regulate c-Myc turnover are Skp2 and FBXW7. Studies have shown that knock-down of FBXW7 increases c-Myc expression and its activity, and FBXW7 -/- mouse embryonic stem cells have elevated c-Myc expression levels [15]. FBXW7 regulates leukemia-initiating cell (LIC) homeostasis [16] by controlling c-Myc levels, which correlates precisely with LIC activity. Loss of FBXW7 results in c-Myc accumulation and p53-dependent apoptosis, preventing initiation of Bcr-Abl-induced chronic myelogenous leukemia (CML) and B-cell acute lymphoblastic leukemia (B-ALL) [17]. The phosphorylation of residues Thr58 and Ser62 within the c-Myc CPD is an essential step for FBXW7-mediated degradation and is associated with reduced tumor cell proliferation and survival $[1,12,15]$. However, specific mutations at Thr58 and Ser62 that can prevent c-Myc degradation by FBXW7 are found in many cancers $[12,15,18]$. In fact, a c-Myc mutation at residue Thr58 is the most frequently mutated c-Myc site in human B-cell lymphomas [18]. Unlike the homotypic poly-ubiquitination that occurs with FBXW7-mediated c-Myc degradation, SCF, along with the Ubiquitin Conjugating Enzyme E2 D1 (UbcH5), can add heterotypic poly-ubiquitination chains to the $\mathrm{N}$-terminal of c-Myc. This action antagonizes FBXW7-mediated degradation and stabilizes c-Myc protein levels [19]. Therefore, different poly-ubiquitination chains determine different fates of the c-Myc protein. Finally, ubiquitin-specific proteases (USP) Usp28 and Usp36 have also been shown to counteract FBXW7-mediated c-Myc degradation by deubiquitinating c-Myc [20, 21].

\section{Cyclin E}

Cyclin E/cyclin-dependent kinase Cdk2 (cyclin E/CDK2) regulates cell cycle progression by licensing DNA replication at the G1-S phase transition [22]. Abnormal cyclin $\mathrm{E}$ expression is observed in many cancers [23-25]. Mutations of FBXW7 that impair its ability to degrade cyclin $\mathrm{E}$ have been reported to result in chromosome instability, aneuploidy, and to play a role in tumorigenesis [23, 24, 26, 27]. In FBXW7 knock-out mice, elevated levels of cyclin $E$ are correlated with an increased rate of DNA synthesis [28]. During normal cell cycle, cyclin E amounts need to be regulated in order to reduce and limit the amount of cyclin $\mathrm{E}$ in the cell. The phosphorylation of cyclin E by cyclin dependent kinase 2 (CDK2) and GSK3 $\beta$, at Ser384 and Thr380, respectively, are essential for FBXW7-mediated degradation [2, 4]. During interphase of the cell cycle, protein phosphatases, such as PP2A-B56, have been shown to dephosphorylate 
Ser384, leading to reduced FBXW7 degradation and higher levels of cyclin E [29]. Additionally, phosphatase PP2A-B55 can dephosphorylate the $\mathrm{N}$ - and the $\mathrm{C}$-terminal phosphodegrons of cyclin $\mathrm{E}$ within an active CDK2 complex [30]. This action opposes FBXW7-mediated degradation and prevents autocatalytic degradation of cyclin E. An oncogenic active Ras signaling pathway has been shown to inhibit FBXW7-mediated cyclin E degradation by activating the mitogen-activated protein kinase (MAPK) pathway [31]. Mechanically, activated Ras impaired the interaction between FBXW7 and cyclin E, and hence reduced cyclin E ubiquitination [31].

\section{Notch1}

Notch ((Drosophila) Homolog 1 Translocation-Associated) proteins are a family of receptors responsible for activation of Notch signaling pathways. The Notch pathway has numerous cellular effects, including roles in development, cellular differentiation, regulation of stem cells, cellular proliferation, and cell death [32]. Physiological activation of Notch involves interactions between the Notch receptor and a ligand of the Delta/Serrate/LAG-2 family. This triggers a series of proteolytic cleavages within Notch that release the nuclear intracellular domain (NICD). NICD then translocates to the nucleus to activate transcription of target genes [33]. Notch de-regulation has been linked to numerous cancers and inheritable, cardiovascular, and cerebrovascular diseases [34]. Termination of Notch signaling requires phosphorylation of NICD in the PEST domain through the cyclin C/CDK8 complex or through cyclin $\mathrm{C}$ complexing with CDK19 or CDK3 [35, 36]. These interactions cause phosphorylation at residues Thr2512, Ser2514, and Ser2517. In addition, GSK $3 \alpha / \beta$ and ILK (Integrin-linked kinase) also phosphorylate NICD for FBXW7-mediated degradation [37-39]. This event is mediated by GSK3 $\alpha / \beta$ phosphorylation at Thr1851, Thr2123, and Thr2125 and ILK phosphorylation at Ser2173. Genetic mutations of NICD preventing FBXW7-mediated turnover have been demonstrated in many hematopoietic and solid tumors [40, 41]. In addition to the Notch1 mutations, more than $30 \%$ of pediatric T-ALL patients harbor FBXW7 mutations [42]. These mutations have been shown to disrupt the interaction between FBXW7 and NICD [42, 43]. Importantly, T-ALL cells carrying FBXW7 mutations demonstrate an extended NICD protein half-life and are generally resistant to the Notch inhibitor, MRK-003 GSI [42, 43].

\section{MCL-1}

Myeloid cell leukemia-1 (Mcl-1) belongs to the BCL-2 family and regulates apoptosis in normal and cancer cells [44]. Mcl-1 amplification is a common genetic abnormality observed in human cancer [45]. Mcl-1 has a very short half-life and its expression is tightly regulated. FBXW7 interacts with and targets Mcl-1 for degradation following the phosphorylation of Ser159 and Thr163 present in the CPD of Mcl-1 [46, 47]. These two sites represent the major phosphorylation targets for GSK3, with Ser121 serving as an additional minor phosphorylation site. Studies have shown that an AKT inhibitor (API-1), which is upstream of GSK3, requires both FBXW7-dependent and FBXW7-independent (through $\beta$-TrCP) targeting in order to mediate full degradation of Mcl-1 [46]. In addition, mTOR complex 2 (mTOR2) has been shown to inhibit GSK3-dependent FBXW7-mediated degradation of Mcl-1 [48]. This event leads to stabilization and increased levels of Mcl-1. In human T-ALL, loss of FBXW7 is associated with Mcl-1 overexpression and increased susceptibility to the multi-kinase inhibitor Sorafenib, and increased resistance to the BCL2 antagonist ABT-737 [47]. Furthermore, mutation of FBXW7 in squamous cell carcinoma (SCC) has been shown to increase Mcl-1 expression and promote resistance to standard chemotherapy [49].

\section{mTOR}

The mammalian target of rapamycin (mTOR) is a serine/ threonine kinase and member of the phosphoinositide 3-kinase-related kinase (PIKK) family, and plays important roles in cell proliferation, metabolism, survival, and autophagy. mTOR resides in a protein complex that contains either mTORC1 or mTORC2. mTOR turnover is regulated by FBXW7-mediated ubiquitination and degradation [50]. FBXW7 knock-outs show loss of mTOR, p-mTOR, and S6-kinase (p-SK6), a known downstream target. RICTOR (Rapamycin-insensitive companion of mammalian target of rapamycin), a component of mTOR2, can also be regulated by FBXW7 [51]. This event is dependent upon GSK3 phosphorylation of RICTOR at residue Thr1695 [51]. In contrast, activation of AKT inhibits GSK3 activity, thus up-regulating RICTOR expression and mTORC2 activity. This suggests that FBXW7 may act as a switch to regulate mTORC2/ AKT activity [51]. Radiation-induced loss of mTOR is associated with activation of FBXW7 expression, resulting in FBXW7-dependent degradation of mTOR [52]. Furthermore, rapamycin treatment delays tumor development in FBXW7/p53 double heterozygous (FBXW7+/-; p53+/-) mice, but not p53 single heterozygous $(\mathrm{p} 53+/-)$ mice, after exposure to radiation [52]. These observations suggest the importance of mTOR and FBXW7 in radiation-induced tumor formation. Moreover, increased mTOR expression in FBXW7 deleted or mutated cells sensitizes these cells to rapamycin treatment [50]. Therefore, inactivation of FBXW7 may be used as a biomarker to identify patients that may respond better to rapamycin treatment [50].

\section{Jun}

Activator protein 1 (AP1) dimers are mainly composed of Jun-Fos and Jun-ATF2 proteins, important factors in 
controlling cell proliferation, stress responses, and apoptosis. Under physiological conditions Jun expression is controlled by FBXW7-mediated ubiquitination and proteasome degradation. Mechanistically, FBXW7 requires GSK3 $\beta$-mediated C-terminal phosphorylation of c-Jun at Thr239 and Ser243 [53]. In contrast, the phosphorylation at the $\mathrm{N}$-terminus of c-Jun by Jun $\mathrm{N}$-terminal kinases (JNKs) significantly increases its half-life. Further studies showed that the receptor for activated C-kinase 1 (Rack1) can form a complex with c-Jun and FBXW7, but only recruits C-terminal phosphorylated c-Jun. Hence, c-Jun phosphorylated at its N-terminus is excluded from the FBXW7-Rack1 complex and protected from ubiquitination and degradation. The importance of FBXW7 regulation of Jun is further demonstrated in gut-specific (Villin-Cre) FBXW7 knock-out mice. These mice develop adenoma at 9-10 months of age and present elevated c-Jun expression [54]. In contrast, ectopic expression of FBXW7 in renal cell carcinoma (RCC) cells reduces c-Jun expression and leads to reduced cellular proliferation and apoptosis [55].

\section{Aurora kinase A (AURKA)}

AURKA is a serine/threonine kinase playing an essential role in the regulation of the mitotic checkpoint, spindle assembly checkpoint (SAC), centrosome duplication, and cytokinesis. BUB and MAD proteins inhibit the ubiquitin ligase activity of the Anaphase Promoting Complex/Cyclosome (APC/C) during mitosis to ensure cells with unaligned chromosomes do not prematurely enter anaphase. In contrast, FBXW7 controls the E3 ligase activity of APC Cdh1 by modulating the expression of cyclin E. Thus, in FBXW7-deficient cells, increased cyclin E expression inactivates APC Cdh1 via direct phosphorylation of Cdh1. Increased expression of AURKA is associated with aneuploidy, which may trigger apoptosis or cellular transformation. AURKA is located on chromosome 20q13.2, a region commonly amplified in cancer. Studies have demonstrated that loss of phosphatase and tensin homologue deleted on chromosome 10 (PTEN) results in an increased half-life of AURKA by reducing FBXW7-dependent degradation of AURKA, leading to genetic instability $[56,57]$. Further studies identified that Thr217 and Glu221 amino acids were indispensable for direct interaction between AURKA and FBXW7 and that Ser245 and Ser387 phosphorylation by GSK3 $\beta$ was required for FBXW7-mediated proteasome degradation of AURKA [58]. Overexpression of FBXW7 reduces expression of AURKA in ovarian cancer cells [59]. In addition, radiation-induced tumor latency is shorter in FBXW7 heterozygous and PTEN heterozygous knock-out mice (FBXW7+/-; PTEN+/-) compared to FBXW7 heterozygous knock-out mice (FBXW7+/-) and PTEN heterozygous knock-out mice (PTEN+/-) [58]. Therefore,
FBXW7 can cooperate with PTEN to target AURKA and suppress tumorigenesis [58].

\section{Oncogenic activities of FBXW7}

The role of FBXW7 as a tumor suppressor is well established. However, novel oncogenic FBXW7 mutants recently identified in human T-cell leukemia virus (HTLV-I) transformed adult T-cell leukemia (ATL) cells suggest a possible oncogenic role for FBXW7. FBXW7 mutations D510E and D527G demonstrate transforming activity when co-expressed with either HTLV-I's oncoprotein Tax, mutated p53 (R276H), or mutated c-Myc (F138C) [60]. These observations are relevant since these mutations in p53 and c-Myc have been previously detected in a variety of human cancers [60]. The transforming activity of FBXW7 mutants was further demonstrated by their ability to provide IL-2-independent growth of Tax-immortalized human $\mathrm{T}$ cells and by increasing tumor formation in a xenograft mouse model of ATL [60]. These data suggest that FBXW7, normally a tumor suppressor, may act as an oncogene under specific circumstances. Other reports have also described oncogenic activity for FBXW7 [61]. In epidermal cells, loss of presenilin (PS), which is a catalytic component of gamma-secretase, leads to up-regulation of FBXW7 and subsequent stabilization of epidermal growth factor receptor (EGFR) [61]. Recently, FBXW7 was shown to be recruited to radiation-induced DNA damage sites upon phosphorylation by ATM Serine/Threonine Kinase (ATM) [62]. FBXW7 promoted K63 ubiquitination of the DNA repair protein X-Ray Repair Cross Complementing 4 (XRCC4) at K296, thereby enhancing the binding of XRCC4 to the Ku70/80 heterodimer and facilitating non-homologous end joining (NHEJ) repair of double DNA strand breaks (DSBs) [62]. NHEJ is often error-prone and results in the loss of nucleotides following repair. This can then lead to increases in DNA damage and genomic instability. While these events increase resistance of cells to radiation, it may also allow survival and accumulation of genetic defects in cells that should enter apoptosis and this could ultimately culminate in cellular transformation.

\section{Inactivation of FBXW7 functions \\ Regulation of FBXW7 expression, ubiquitination, and degradation:}

The expression of FBXW7 mRNA and protein is detectable in all tested human tissues [63]. FBXW7 protein expression is high in many normal human tissues, with no tissue showing low expression of the FBXW7 protein [63]. Examination of FBXW7 protein expression by immunostaining shows that compared with normal primary tissues, FBXW7 protein expression is greatly reduced in carcinoid, glioma, liver, lung, melanoma, pancreatic, prostate, renal, skin, testis, thyroid and urothelial cancers [63]. 
FBXW7 expression and activity can be regulated through genetic mutations, RNA silencing, post-transcriptional mechanisms, and homodimerization. In addition to miRNA and lncRNA, protein deregulation can affect FBXW7 gene expression. For example, Hes5, a downstream target of Notch, has been shown to inhibit FBXW7 $\beta$ promoter gene expression, forming a feedback loop between Notch, Hes5, and FBXW7.

\section{Non-coding microRNA (miRNA) and long non-coding RNA} (IncRNA) regulation of FBXW7 gene expression:

miRNAs can bind to the 3' untranslated region (UTR) of a gene and target the mRNA for degradation and prevent protein translation. The miRNA miR- 548 has been shown to bind directly to the 3'UTR of FBXW7 and reduce the levels of FBXW7 mRNA and protein [64]. In addition, the IncRNA, IncRNA-MIF, has been shown to counteract the action of miR- 548 by acting as a miR- 548 sponge [64]. Overexpression of IncRNA-MIF can therefore increase the mRNA and protein expression of FBXW7 and inhibit the expression of FBXW7 targets such as c-Myc or c-Jun. In the same manner, the lncRNAs TINCR, CASC2, and MALAT1 can also act as sponges to block inhibition of FBXW7 by miR-544a, miR-367, and miR-155, respectively [65-67]. Additional miRNAs that have been shown to bind and inhibit the 3'UTR of FBXW7 include miR-223, miR-25, miR-27, miR-32, miR-92, miR-155-3p, miR-182, and miR-503 [68-73]. The majority of these miRNAs inhibited FBXW7 downstream targets, such as cyclin E, Mcl-1, c-Jun, and c-Myc, and correlated with FBXW7 expression in various tumorigenic patient samples. In several of these cases, the correlation between a single miRNA and the gene expression of FBXW7 in patient samples was relatively weak, suggesting that more than one single miRNA is required or additional mechanisms exist to regulate FBXW7 gene expression.

\section{Epigenetic regulation of FBXW7 expression}

FBXW7 $\alpha$ is ubiquitously expressed across multiple cell lines and patient samples and has broad tissue distribution. In contrast, FBXW7 $\beta$ shows differential expression in cell lines and even in tissue localization. The FBXW7 $\beta$ promoter can be epigenetically regulated through DNA and histone modifications, and is methylated in $43 \%$ of a variety of cancer cell lines and $51 \%$ of primary breast cancer tumors [74]. Methylation correlated with a decrease in FBXW7 $\beta$ gene expression. Unexpectedly, methylation of FBXW7 is associated with a longer overall survival period in lymph node-positive breast cancer patients, although it is also associated with high-grade tumors [74]. Samples from ovarian cancer patients show decreased FBXW7 expression in patients with mutated p53 [75]. Mutations in p53 are associated with hypermethylation of the FBXW7 promoter, resulting in decreased FBXW7 gene levels. This may result from p53's ability to increase expression of the DNA methyltransferase 1 (DNMT1). In addition to DNA modifications, histone modifications are reported to control FBXW7 expression. Enhancer of zeste homolog 2 polycomb repressive complex 2 (EZH2) is a histone methyltransferase involved in epigenetic silencing of genes. EZH2 causes the addition of three methyl groups onto the histone H3 residue, H3K27me3, of FBXW7 [76]. This leads to silencing of FBXW7 gene function, which in turn activates the Notch signaling pathway [76]. Interestingly, EZH2 has been reported to be a substrate of FBXW7 in pancreatic cancer cells and is negatively correlated with FBXW7 expression in human pancreatic cancer samples [77].

\section{Genetic regulation of FBXW7}

Analyses of the Catalogue of Somatic Mutations in Cancer (COSMIC) database revealed that FBXW7 has the highest mutational frequency among all F-box and WD repeat domain containing family members (Table 1 ) and SCF ubiquitin ligase complexes (Table 2). FBXW7 mutations may reduce the protein's ability to form SCF complexes and/or alter the complex conformation leading to a non-functional complex. FBXW7 interacts with SKP1 through the F-box-like domain and mutations of FBXW7 in the F-box-like domain have been reported in the COSMIC database (Fig. 2). Whether FBXW7 mutations in the F-box domain may also impair interactions with SKP1 needs to be further investigated. We performed COSMIC database meta-analyses and found an overall FBXW7 mutation rate of $2.54 \%$ across all human tumors $(n=1216 / n=47,844)$ [78]. Among these, $72.70 \%$ $(884 / 1216)$ of FBXW7 mutations are substitution missense mutations and $13.82 \%(168 / 1216)$ are substitution nonsense mutations. Insertion/deletion mutations represent $7.89 \%$ of FBXW7 mutations. Further analyses of tissue distribution of FBXW7 mutations revealed that the endometrium (85/918: 9.26\%), large intestine (346/4512: 7.73\%), cervix (24/411: 5.84\%), small intestine (8/143: 5.59\%) and stomach (51/1182: $4.31 \%$ ) are the top five tumor tissues harboring FBXW7 point mutations (Fig. 3). The vast majority of FBXW7 mutations detected in cancer cells are single nucleotide changes, predominantly missense substitutions. The most common mutations are found in mutational hotspots, R505, R465 and R479, codons located in the substrate binding domain also known as tryptophan-aspartic acid motif (WD40) and represent $25.41 \%$ (309/1216), 9.29\% (113/1216) and $13.40 \%$ (163/1216), respectively, of all FBXW7 mutations (Fig. 4) [78]. In addition, residues R278, R367, G423, S582 and R689 are mutated in more than 20 separate cancer cases according to the COSMIC database (Fig. 4). 
Table 1 Gene Family: F-box and WD repeat domain containing (FBXW)

\begin{tabular}{llllll}
\hline Gene & Mutation Percentage & Tested Samples & Simple Mutations & Fusions & Coding Mutations \\
\hline FBXW7 & 2.54 & 47,844 & 1216 & 0 & 1216 \\
FBXW10 & 0.58 & 31,969 & 184 & 0 & 184 \\
BTRC & 0.53 & 32,582 & 173 & 0 & 173 \\
FBXW8 & 0.47 & 32,150 & 151 & 0 & 151 \\
FBXW5 & 0.43 & 32,062 & 137 & 0 & 137 \\
FBXW12 & 0.41 & 32,062 & 133 & 0 & 133 \\
FBXW11 & 0.39 & 32,195 & 124 & 0 & 124 \\
FBXW4 & 0.30 & 32,062 & 96 & 0 & 96 \\
FBXW2 & 0.30 & 31,879 & 95 & 0 & 0 \\
CDRT1 & 0.14 & 31,947 & 45 & 27 & 0 \\
FBXW9 & 0.08 & 32,062 & 27 & 45
\end{tabular}

Previous studies have reported that mutations in the WD40 domain prevent interactions between FBXW7 and its known substrates. Recent studies suggest that specific FBXW7 mutations can affect degradation of specific substrates. In fact, FBXW7 D510E retains its ability to target and degrade cyclin E, Mcl-1, and c-Myc, but not NICD [60]. The reason for FBXW7's D510E lack of NICD degradation is unknown, and FBXW7 D510E shows higher oncogenic activity compared to other FBXW7 mutations [60].

To identify potential gene mutation co-occurrences with FBXW7 mutations, we retrieved the 50 most frequently mutated genes from the COSMIC database. We then used the cBioPortal to analyze co-occurrence in the Cancer Cell Line Encyclopedia (CCLE). We found 27 gene mutations that demonstrate significant co-occurrence with FBXW7 mutations (Fig. 5). Among these, as much as $47 \%$ of FBXW7 mutant cells also harbor APC mutations. KRAS (Kirsten Rat Sarcoma Viral Proto-Oncogene), ATM, and PTEN were also among the most mutated genes in FBXW7-mutated cancer cells. Whether the combination of FBXW7 mutation along with specific genes can accelerate cancer progression warrants further investigation. FBXW7 dimerization increases binding strength with substrates, which is particularly important for substrates with weak CPDs, like cyclin E. Since FBXW7 mutations are generally heterozygous, how mutations may affect protein function and target degradation may fluctuate [79]. Dimerization enhances the trans-auto-ubiquitination and reduces FBXW7 protein half-life [80]. In contrast to
FBXW7 monomers, FBXW7 dimers can bind to multiple CPDs within the target protein and allow for ubiquitination to occur at multiple sites. This has been shown for FBXW7 targets, such as cyclin E. Dimerization also allows for the binding of FBXW7 to suboptimal CPD sequences. As for other dimerizing factors, mutations that do not affect the dimerization domain may exert a dominant negative effect, and hence be more deleterious than mutations resulting in allelic loss [81]. Therefore, it is expected that the functional consequences of FBXW7 mutations upon substrates may be quite variable, and responses to targeted therapies might also be unpredictable $[82,83]$.

\section{Post-translational regulation of FBXW7: Dimerization, localization, and auto-ubiquitination}

Alterations in FBXW7 cellular distribution can impair its ability to interact with and degrade oncoproteins. Nucleophosmin (NPM) is frequently mutated in acute myelogenous leukemia (AML) and is essential for nucleolar localization and stabilization of FBXW7Y [84]. Loss of NPM destabilizes FBXW7 $\gamma$ and results in c-Myc accumulation [84]. In addition, Protein Kinase C (PKC) phosphorylates FBXW7 $\alpha$ at Ser10 and Ser18 [85]. Phosphorylation at Ser10 leads to inhibition of one of FBXW7's nuclear localization signals (NLS); however, full redistribution of FBXW7 $\alpha$ to the cytoplasm requires additional disruption of FBXW7 $\alpha$ 's second NLS. PKC may facilitate cellular transformation by inactivating FBXW7 $\alpha$ through cytoplasmic sequestration. Finally, the EBP1 (ErbB3 receptor-binding protein) gene encodes two alternatively spliced isoforms:

Table 2 SCF-Fbw7 Protein Complex

\begin{tabular}{llllll}
\hline Gene & Mutation Percentage & Tested Samples & Simple Mutations & Fusions & Coding Mutation \\
\hline FBXW7 & 2.54 & 47,844 & 1216 & 0 & 1216 \\
CUL1 & 0.71 & 32,150 & 228 & 0 & 228 \\
SKP1 & 0.09 & 32,150 & 30 & 0 & 30 \\
RBX1 & 0.05 & 32,150 & 17 & 0 & 17 \\
\hline
\end{tabular}




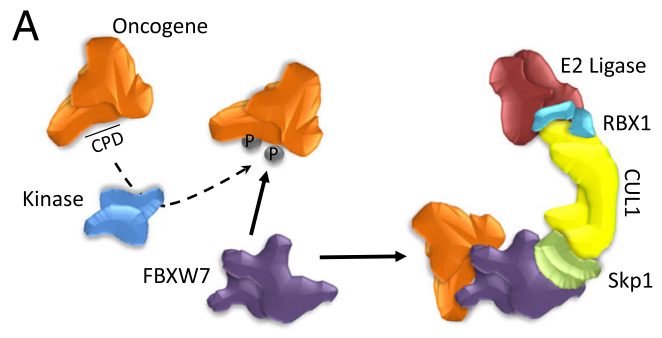

B

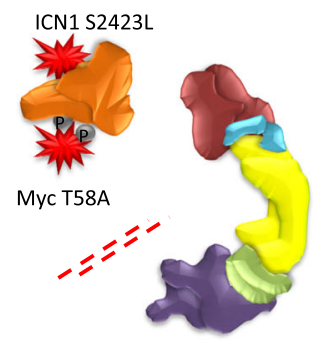

C

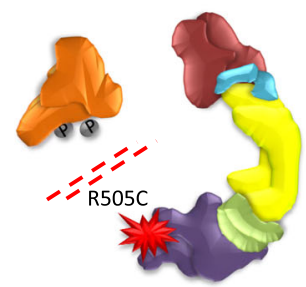

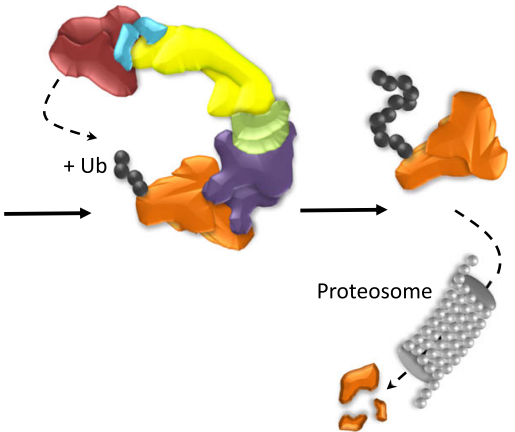

D

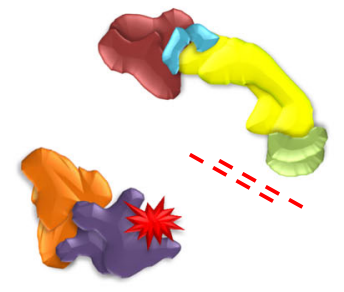

Fig. 2 Genetic mutations impair FBXW7-mediated oncogene degradation. (a) FBXW7 recognizes its substrate through a conserved CDC4 phosphodegron (CPD) motif, which requires the substrate to be phosphorylated by a kinase. The SCF complex, which consists of SKP1, CUL1, RBX1 and FBXW7, interacts with the substrate through FBXW7 and adds ubiquitin (Ub) to the substrates. Poly-ubiquitinated substrates are then targeted by the proteasome for degradation. (b-d) The FBXW7-substrate interaction can be de-stabilized through: mutations in the substrate that prevent the interaction with FBXW7 (b), mutations in the WD40 domain of FBXW7 that impair its ability to interact with the substrate (c), and mutations in the FBXW7 F-box domain that inhibit its ability to interact with the substrate (d). These mutations have been reported in human cancers and may impair the formation of the SCF complex and stabilize FBXW7 substrates

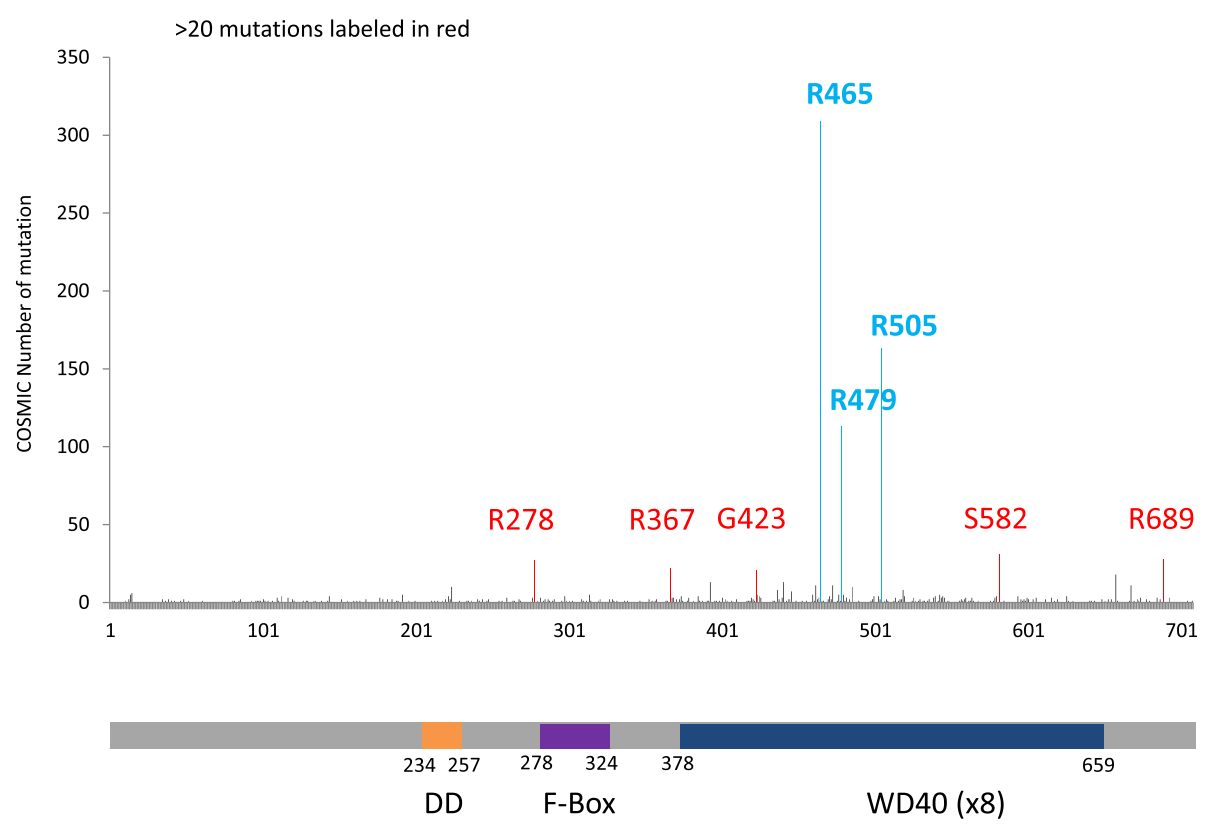

Fig. 3 The distribution of FBXW7 mutations in the FBXW7 genome. The numbers of FBXW7 genetic alternations are retrieved from the COSMIC database. FBXW7 residues with a mutation number higher than 20 are highlighted in red and 3 FBXW7 hotspot mutations are labeled in blue. The bottom panel indicates FBXW7 protein domains (DD: dimerization domain amino acid 234-257, F-Box-like domain: amino acid 281-325 and WD40: amino acid 374-650) 
FBXW7 mutations in different tissues (COSMIC database)

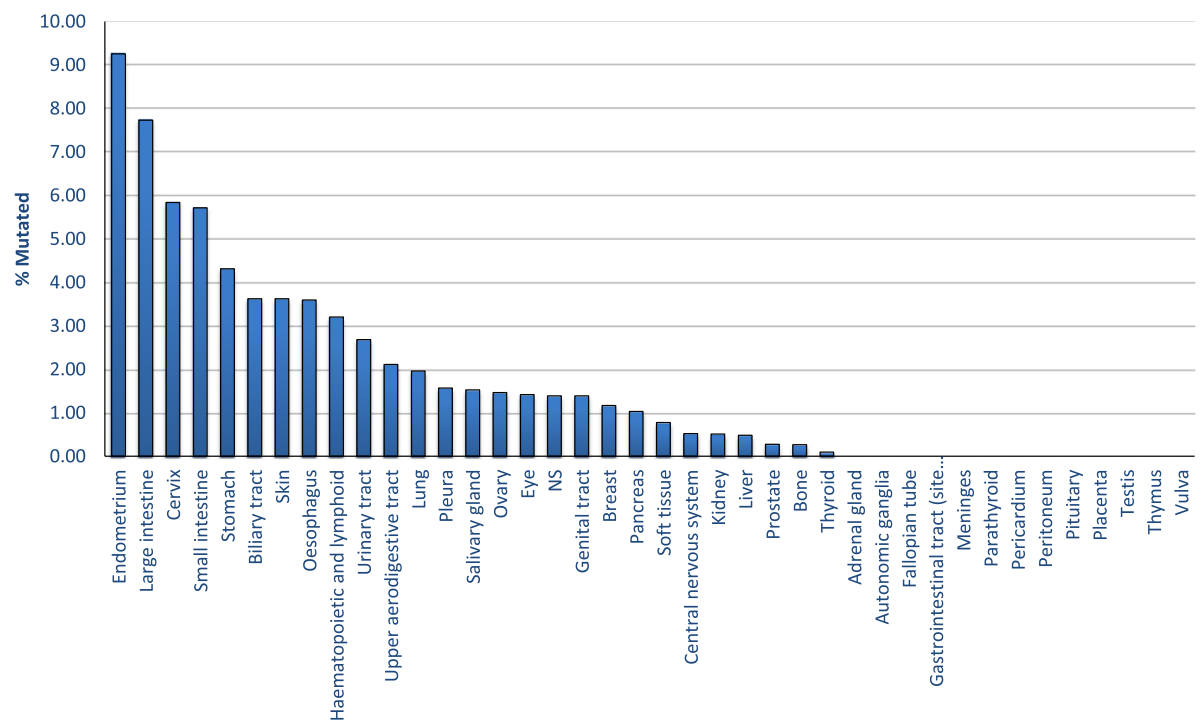

Fig. 4 The distribution of FBXW7 mutations in different human tissues. The percentage of FBXW7 mutations varies from tissue to tissue. The endometrium has the highest percentage of FBXW7 mutations (9.26\%). In contrast, no FBXW7 mutation is found in the adrenal gland, autonomic ganglia, fallopian tube, gastrointestinal tract (site indeterminate), meninges, parathyroid, pericardium, peritoneum, pituitary, placenta, testis, thymus and vulva tissues

P48 and P42 [86]. P48 forms a negative feedback loop with FBXW7 $\alpha$, whereby FBXW7 $\alpha$ degrades P48 in a GSK3-dependent manner, and P48 is able to bind FBXW7 $\alpha$ and sequester it in the cytosol. This prevents FBXW7 $\alpha$ from degrading its substrates [86]. In contrast, P42 acts as an adaptor to stabilize the interaction between FBXW7 and its substrates, which enhances FBXW7-mediated degradation [86]. The EBP2 (EBNA1-binding protein 2) protein also facilitates different isoforms of FBXW7 nucleolar distribution [87]. Some viral oncoproteins can inactivate FBXW7 function. For example, the large T-antigen of SV40 virus can act as a decoy and target FBXW7 $\gamma$ to the nucleoplasm instead of the nucleolus [88].

FBXW7 function can be regulated through auto-ubiquitination. Peptidyl-prolyl cis-trans isomerase NIMA-interacting 1 (Pin1) has been shown to negatively regulate FBXW7 protein expression [89]. Mechanically, Pin1 interacts with FBXW7 in a phosphorylation-dependent manner and binds to the Thr205-Pro region of FBXW7. This introduces a conformational change in FBXW7, leading to decreased dimerization and increased FBXW7 self-ubiquitination and degradation [89]. Depletion of Pin1 results in up-regulation of FBXW7 and reduced levels of FBXW7 substrates such as Mcl-1, and sensitizes cancer cells to the chemotherapy drug Taxol [89]. Consistently, Sorafenib, which is associated with reduced expression of Pin1, leads to FBXW7 stabilization and destabilization of Mcl-1 [90]. The extracellular signal-regulated kinase (ERK) can also interact with and phosphorylate FBXW7 at Thr205, leading to FBXW7 ubiquitination and proteasome-mediated degradation [91]. The significance of ERK-mediated phosphorylation of FBXW7 was demonstrated by the FBXW7 mutation Thr205A providing resistance to ERK-mediated phosphorylation and suppressed pancreatic cancer cell proliferation and tumorigenesis [91]. In addition to the Thr205 site, polo-like kinase 2 (Plk2) interacts with and phosphorylates FBXW7 on Ser176 (and to a lesser extent Ser25 and Ser349), triggering FBXW7 proteasome degradation [92]. In fact, the oncogenic activity of Plk2 can be reversed by restoring FBXW7 expression [93]. Members of the SCF ubiquitin ligase complexes can also control FBXW7 stability. For example, CSN6, a component of the COP9 signalosome, positively regulate E3 ubiquitin ligases. CNS6 regulates neddylation of Cullin1 (an adaptor for FBXW7 in the SCF ubiquitin ligase complex) and promotes the auto-ubiquitination and degradation of FBXW7 [94]. On the other hand, mono-allelic deletion of CSN6 decreases Cullin1 neddylation, stabilizes FBXW7, and compromises lymphomagenesis in an E $\mu-M y c$ mouse model [94]. Deletion of Glomulin (Glmn), a member of the SCF complex that interacts with Rbx1, reduces FBXW7 expression by stimulating Rbx1-mediated ubiquitination of FBXW7 [95]. In all, there are over 300 different interacting partners for FBXW7 that are described in the BioGRID database [96]. Among them, some have been shown to affect FBXW7 stability. For example, the family with sequence similarity 83, member D (FAM83D) interacts with FBXW7 and induces its proteasome-dependent degradation. FAM83D-mediated 


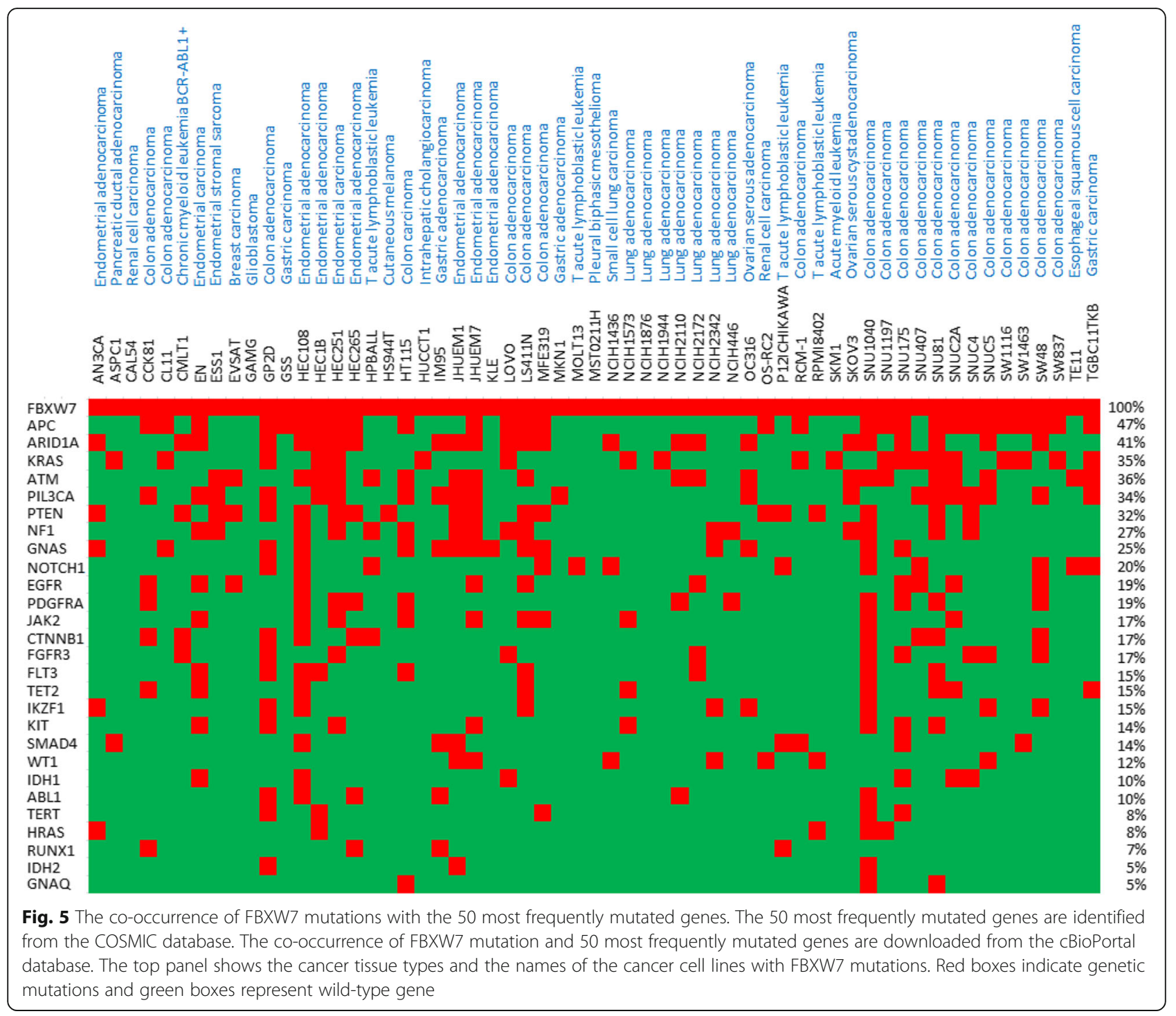

FBXW7 down-regulation is associated with an increase in the expression of FBXW7 substrates, such as c-Myc, mTOR and c-Jun, in breast cancer; and FAM83D is frequently deregulated in breast and colon cancer [97, 98]. The auto-ubiquitination and stability of FBXW7 can be reversed by the deubiquitinase (DUB) Usp28 [99]. Although single allele deletion of Usp28 allows FBXW7-mediated substrate degradation, it has little effect on FBXW7 stability. However, Usp28 null cells show Pin1-dependent, FBXW7 degradation and accumulation of FBXW7 substrates [99].

\section{Disruption of FBXW7-substrate interactions}

The FBXW7 WD40 domain forms a $\beta$-propeller structure involved in substrate binding to the CPD region of the targeted protein. Mutations in specific CPD residues can disrupt FBXW7-mediated targeting and degradation. Hotspot mutations within the CPD motif of c-Myc are detected at residue Thr58 in Burkitt's lymphoma patient samples. Mechanistically, mutated Thr58 can no longer be phosphorylated by GSK3, resulting in increased c-Myc half-life and higher oncogenic potential [100]. Pro57 is also highly mutated in Burkitt's lymphoma cells and is required for Thr58 phosphorylation. COSMIC database analyses revealed that mutation of Pro2514 within the Notch1 CPD (FLTPSPES) accounts for as much as $14.63 \%$ of the total Notch 1 mutations found across all human cancers (Fig. 1). Likewise, COSMIC database analyses revealed that a Pro59 mutation within the c-Myc CPD accounted for more than $9 \%$ of all c-Myc mutations found in human cancer (Fig. 1). Proline mutations are predicted to have serious consequences for protein conformation and the role of these mutations in preventing Notch1 or c-Myc binding to FBXW7 warrants further analyses. In the absence of genetic mutations, alterations in signaling pathways controlling phosphorylation of FBXW7 targets 
play an important role. Along these lines, because GSK3 $\beta$ mediated phosphorylation is required for degradation of c-Myc [12, 101], cyclin E [4] and MCL1 [46], any signaling pathway that affects GSK3 $\beta$ activity can have a profound impact on FBXW7's ability to perform its tumor suppressor activities. In addition, de-regulation of GSK3 upstream modulators also leads to altered FBXW7 functions. As stated earlier, this is the case for AURKA regulation by PTEN. Loss of PTEN leads to alterations in the PI3K/AKT/ GSK3 pathway that stabilizes AURKA [58]. In addition to GSK3 $\beta$, other kinases are also important in FBXW7 functions. For instance, CDK5-mediated EZH2 phosphorylation is essential for FBXW7-mediated EZH2 degradation [77] and CDK8 is required for Notch1 degradation [35]. In contrast to reducing FBXW7-substrate binding, some proteins are reported to increase FBXW7-substrate binding, hence reducing oncoprotein expression. For instance, amplified in breast cancer 1 (AIB1) is a transcriptional coactivator that activates the transcription of nuclear receptors and other transcription factors [102]. PTEN has been shown to interact with both AIB1 and FBXW7 [102]. This interaction brought AIB1 and FBXW7 $\alpha$ together and accelerated AIB1 degradation [102]. Furthermore, Alpha-synuclein (SNCA) promotes the degradation of the NICD domain via directly interacting with FBXW7 and promoting the interaction between Notch1 and FBXW7 [103]. Finally, a direct competition mechanism and displacement of FBXW7 targets by viral proteins has been reported. For example, Kaposi's sarcoma-associated herpesvirus (KSHV) latency-associated nuclear antigen (LANA) can form a complex with FBXW7. The LANA/FBXW7 complex inhibits NICD ubiquitination and degradation by competing with NICD for binding to FBXW7 [104]. Hence, KSHV-infected tumor cells increase cell proliferation by reducing FBXW7-mediated Notch degradation. Merkel cell polyomavirus (MCV) contains small $\mathrm{T}$ (ST) and large T (LT) viral oncoproteins that are involved in aggressive human skin cancer [105]. While the LT viral oncoprotein is a substrate of FBXW7, the ST viral oncoprotein contains an LT-stabilization domain (LSD) inhibiting FBXW7 interaction with the LT viral oncoprotein [105].

\section{Clinical significance of FBXW7 loss of function in human cancers}

Acute lymphoblastic leukemia

Conditional knock-out of FBXW7 in hematopoietic cells or T cells is sufficient to cause T-ALL or thymic lymphoma by increasing Notch1 and c-Myc expression [7, 106]. However, FBXW7 hotspot mutation knock-in mice (FBXW7mut/+) do not develop spontaneous leukemia, demonstrating a subtle difference between FBXW7 missense mutations and homologous deletion. When combining FBXW7 deletion/mutation with p53 suppression, loss of PTEN, or active Notch, an FBXW7 deletion/mutation enhances tumorigenesis $[7,16,58]$. Notch and
NF- $\mathrm{kB}$ can bind to the miR-223 promoter and activate miR-223 expression [107]. Studies show that Notch-mediated activation of miR-223 suppresses FBXW7 in T-ALL; and miR-223 and FBXW7 expression are inversely correlated in T-ALL patient-derived xenografts [107]. The oncogenic transcription factor, T-cell acute lymphocytic leukemia 1 (TAL1/SCL), is aberrantly expressed in more than $60 \%$ of T-ALL patients [108]. TAL1 binds to the miR-223 promoter and increases miR-223 expression. Silencing TAL1 increases expression of FBXW7 and lowers expression of FBXW7 substrates, such as c-Myc, Notch1 and cyclin E [108]. Therefore, it appears that miR-223 plays an essential role in FBXW7 activities. In addition, several studies demonstrate a role for miR-27a in ALL. MiR-27a is up-regulated in pediatric B-ALL and its expression is inversely correlated with FBXW7 expression and disease progression [69].

Results from multiple ALL clinical trials suggests an important role for FBXW7 in patient survival. In 47 patients with pediatric T-ALL, FBXW7 mutations are not associated with treatment outcome [109]. This is equivalent to the 88 T-ALL patients who were treated on the UKALLXII/ECOG E2993 protocol, a chemotherapy regime specific to newly diagnosed adult ALL patients [110]. However, in T-ALL patients treated in either the Lymphoblastic Acute Leukemia in Adults-94 trials (LALA-94) $(n=87)$ or the Group for Research on Adult Acute Lymphoblastic Leukemia-2003 trials (GRAALL-2003) $(n=54)$, Notch1/FBXW7-mutated patients have better overall survival and event-free survival compared with other patients, although there is no correlation between Notch1/FBXW7 mutation and clinical biologic features [111]. Glucocorticoid receptor alpha (GR $\alpha)$ may better explain the clinical outcomes in patients with FBXW7 mutations. FBXW7 is known to ubiquitinate and degrade GR $\alpha$. Inhibition of FBXW7 leads to increased glucocorticoid sensitivity, but not other chemotherapy drugs for T-ALL [112].

\section{Colorectal cancer}

FBXW7 mRNA expression is reported to be significantly reduced in colorectal cancer (CRC) [113]. Using a comparative genomic hybridization (CGH) array, over 20\% of CRC patients $(n=130)$ have copy number loss of FBXW7, which correlate with disease progression [113]. Among all human cancers, large intestine cancer harbors the second most frequent FBXW7 mutations (7.73\%). Metastatic CRC (mCRC) patients with FBXW7 missense mutations show shorter overall survival when compared with patients with wild-type FBXW7 [114]. Surprisingly, younger adult colorectal cancer patients have a higher FBXW7 mutation frequency compared to patients diagnosed at an older age [115]. FBXW7 and SMAD4 (SMAD, Mothers Against DPP Homolog 4) mutations 
are prevalent in CRC patients resistant to anti-epidermal growth factor receptor (EGFR) immunotherapy treatment (monoclonal antibodies, Cetuximab or Panitumumab) [116]. In addition, loss of FBXW7 is associated with drug resistance to Oxaliplatin, a drug commonly used to manage mCRC [117].

Analyses of normal colonic epithelial cells against primary and metastatic tumor cells from matched samples show de novo mutations of FBXW7 in synchronous and/ or metachronous liver and/or lung metastases [118]. Furthermore, de novo mutations of FBXW7 occur more frequently in metachronous lung metastases compared with synchronous lung metastases [118]. Similarly, the somatic genetic evolution of colorectal adenocarcinoma (COAD) show that APC and TP53 mutations preferentially happen early, while alterations in FBXW7 and PTEN preferentially occur as a late event [119]. Although FBXW7 mutations are found in $14.3 \%$ of colorectal cancer, no one clinical, pathological or demographic feature is representative of the patients with FBXW7 mutations [120]. In a screen of 96 CRC patients, $10.8 \%$ harbored FBXW7 mutations that are localized in the substrate-binding arginine residues of the $\beta$-propeller blade of FBXW7 (R278, R465, R479, and R505). Importantly, of the 96 CRC patients screened, 8.6\% had co-mutations in FBXW7 and in the oncogene KRAS. This is similar to a study of patients with FBXW7 mutations and CRC, of which $86 \%$ also harbor KRAS mutations [120]. Despite the prevalence of FBXW7 mutations, there is no difference between CRC patients with and without an FBXW7 mutation in the five-year overall survival $[121,122]$. In 822 patients from the VICTOR trial of stage II/III colorectal cancer, mutation of FBXW7 is not associated with disease-free survival [122].

\section{Esophageal and gastric cancers}

FBXW7 mRNA expression is reduced in esophageal squamous cell carcinoma (ESCC) [123]. FBXW7 is also associated with muscle-invasive tumor cases (T2-4), lymphatic-invasive tumor cases, and stage II-IV cases [124]. ESCC patients with loss of FBXW7 copy number show lower FBXW7 expression and poorer clinical prognosis [123]. Loss of heterozygosity (LOH) of FBXW7 is detected in more than $30 \%$ of early-onset gastric cancers (EOGC) and associates with loss of FBXW7 expression in more than 25\% of EOGC [125]. In addition, it is reported that the expression of FBXW7 mRNA is reduced in paired tumor and non-tumor tissues in gastric adenocarcinoma patients [126]. Similarly, single allele deletion of FBXW7 is observed in $45.5 \%$ of gastric tumors, and coordinately, c-Myc amplification is found in $51.5 \%$ of gastric tumor samples [127]. Importantly, immunohisto chemistry shows that down-regulation of FBXW7 protein expression is correlated with poor prognosis and adjuvant chemotherapy response [126]. Aberrant FBXW7 mRNA expression is correlated with lymph node metastasis and tumor stage III-IV [127]. Additional studies show that reduced FBXW7 expression is correlated with lymph node metastasis, tumor size, and poor prognosis in primary gastric cancer [128]. This is mainly due to mutations in p53, which lead to reductions in FBXW7 transcripts [128]. Loss of FBXW7 is not associated with ploidy status [125]. In gastric carcinoma, inhibition of miR-25 induces cell apoptosis through up-regulation of FBXW7 and down-regulation of FBXW7 substrates, such as cyclin E and c-Myc [129]. Additionally, miR-223 is significantly up-regulated in gastric cancer, pancreatic ductal adenocarcinoma, and ESCC [130-132]. ESCC tissues having lower FBXW7 and higher miR-223 expression show poorer overall survival and lower 5-year survival [131]. In gastric cancer, resistance to the DNA damaging drug cisplatin is the most common cause of chemotherapy failure. miR-223 is found to promote cisplatin resistance of human gastric cancer cells by targeting FBXW7 [133].

\section{Hepatocellular carcinoma}

FBXW7 expression is also reduced in hepatocellular carcinoma (HCC) tissues [134, 135]. HCC patients with high histological grade and advanced tumor-node-metastasis stage show lower FBXW7 protein expression [135]. Furthermore, FBXW7 protein expression in HCC tissues is inversely correlated with FBXW7 substrates $\mathrm{c}-\mathrm{Myc}$ and cyclin E [135]. FBXW7 expression is reduced in HCC tissues compared to normal tissue and correlated with tumor differentiation, the incidence of portal or hepatic venous invasion, and metastasis [136]. Furthermore, lower FBXW7 expression is associated with poor clinical pathology features, including large tumor size, high pathological grading, and advanced TNM stage. Importantly, higher FBXW7 mRNA expression is associated with a better five-year overall survival and a longer disease-free survival rate, and expression of FBXW7 could be used as an independent risk factor for HCC recurrence [134, 137]. Similarly, in intrahepatic cholangiocarcinoma (IHCC), FBXW7 expression is associated with disease stage, lymph node metastasis, three-year survival rates, and overall and disease-free survival [138]. Two miRNAs, miR-27b and miR-92a, are overexpressed and can target FBXW7 in HCC. miR-27b inhibits FBXW7 expression and is associated with poor clinical outcome [139], while miR-92a is inversely correlated with FBXW7 expression, increased cell proliferation, and inhibited apoptosis of HCC [140]. The lncRNA CASC2 acts as a sponge for miR-367 in HCC samples [66]. CASC2 enhances FBXW7 expression by inhibiting miR-367 down-regulation of FBXW7. HCC tissues show considerable repression of CASC2, which correlates with metastasis symptoms and poor prognosis. 


\section{Non-small cell lung cancer}

FBXW7 expression is down-regulated in non-small cell lung cancer (NSCLC) and patients with low FBXW7 expression have more aggressive cancer and a shorter survival time [141]. In the clinic, EGFR inhibitor-resistant NSCLC specimens show down-regulation of FBXW7, which is associated with up-regulation of Mcl-1 expression [142]. Reactivation of FBXW7 reduces Mcl-1 expression and sensitizes resistant cells to targeted therapy [142]. In NSCLC, loss of FBXW7 increased the sensitivity of a class I-specific histone deacetylase (HDAC) inhibitor, MS-275 [141]. Tissues with low expression of FBXW7 display increased Mcl-1 and TOP2A (DNA topoisomerase II), an additional FBXW7 target. EGFR-tyrosine kinase inhibitors, such as Erlotinib, have shown some success with EGFR+ or EGFR mutated cancers, however resistance can occur over time. Recently, the miR-223/FBXW7 axis has also been shown to be involved in Erlotinib drug resistance in NSCLC cells [143]. Resistance partially occurs through up-regulation of miR-223, which down-regulates FBXW7. This effect can be reversed by inhibitors targeting either miR-223, AKT or the Notch pathway [143]. FBXW7 is also found to be targeted by miR-25 and miR-367 in NSCLC cells [144, 145]. In addition, p53 mutations can lead to increased expression of miR-25 [146] and overexpression of miR-25 increases NSCLC cell proliferation and migration by targeting FBXW7 [144]. LncRNA MALAT1 is known to reduce metastasis and could serve as a biomarker to predict lung cancer prognosis $[67,147$, 148]. Consistent with the fact that FBXW7 is a direct target of miR-155, MALAT1 was shown to increase expression of FBXW7 by sequestering miR-155 [67]. However, levels of MALAT1 are elevated in NSCLC, which suggests MALAT1 and/or miR-155 do not play a significant role in FBXW7 regulation and implies that the MALAT1/ miR-155/FBXW7 axis may have a tumor suppressor role in lung cancer. This is in contrast to its oncogenic role in glioma patient samples, where tissue samples show reductions in MALAT1 levels compared to non-cancerous brain tissue [67]. FBXW7 is identified as a genuine target of miR-155 in glioma cells. The different roles for MALAT1 may be due to differential expression during different stages of disease or different cell-type specific MALAT1 targets. In fact, MALAT1 is also found to target the miR-124a/STAT3 axis in NSCLC [147].

\section{Breast cancer}

FBXW7 mRNA expression is lower in breast cancer compared with normal tissues [149]. In addition, one report finds that $80 \%$ of breast cancer cell lines harbor alternatively spliced isoforms of FBXW7 [150]. These alternatively spliced forms allow for higher translational efficiency and increased protein expression of FBXW7. Therefore, deregulation of specific alternatively spliced isoforms of FBXW7 may explain the down-regulation of FBXW7 in some human tumors. Mutations in FBXW7 are relatively rare in breast cancer patients. Approximately $1 \%$ of breast cancer patients harbor point mutations in FBXW7, whereas 30\% of breast cancer lines and patients have deletions in the FBXW7 chromosome $4 \mathrm{q} 31[149,151,152]$. When analyzing different breast cancer molecular subtypes (normal-like, luminal A, luminal B, ERBB2 (Erb-B2 Receptor Tyrosine Kinase 2), and basal), ERBB2 and basal tumors show significantly lower FBXW7 expression compared to normallike tumors [149]. In addition, luminal A and B tumors show the lowest FBXW7 mRNA expression in breast cancer subtypes [149]. Similarly, breast cancer patients with high histological grade and hormone receptor-negative tumors show lower expression of FBXW7 [153]. Lower expression of FBXW7 is associated with a high Ki-67 labeling index and positive cyclin E protein expression, both markers of proliferation [153]. Disease-free survival is greater in breast cancer patients demonstrating the highest gene expression of FBXW7 [149].

The association between FBXW7 expression and overall survival is complicated. In ER negative, ERBB2, and basal subtype tumors, patients with higher FBXW7 expression increased their overall survival [149]. However, higher FBXW7 is correlated with poor overall survival in the normal-like subtype [149]. Since FBXW7 can target different substrates in a cell-context dependent manner, further studies are needed to identify the role of FBXW7 in different subtypes of breast cancer. Interestingly, an independent study found that methylation of FBXW7 $\beta$ is associated with favorable prognosis [74]. Additionally, analysis of FBXW7 mutational hotspots in various cancers, including primary breast cancer, show deamination of $5^{\prime}$-methylcytosine within a CG dinucleotide at R479 [5]. The cytosine at this hotspot is methylated, which could lead to inactivation of FBXW7 in breast and other cancerous tissue. Reports have shown that in breast cancer tissue samples miR-32 is overexpressed and inversely correlates with FBXW7 [72]. Overexpression of miR-32 reduces apoptosis and increases cell proliferation and migration by targeting FBXW7 [72]. A similar expression profile is seen for miR-182 in breast cancer tissue, where miR-182 regulates invasiveness, proliferation, and cell cycle progression [154]. miR-182 expressing cells are highly sensitive to hypoxia with up-regulation of HIF- $1 \alpha$ (hypoxia inducible factor-1) and VEGF-A (vascular endothelial growth factor A) [154]. Importantly, overexpression of FBXW7 reverses the increases in HIF- $1 \alpha$ and VEGF-A expression [154]. Preliminary reports may also demonstrate a role for miR-367a in reducing FBXW7 expression in breast cancer samples. 
Table 3 Clinical Significance of FBXW7 Loss-of-function

\begin{tabular}{ll}
\hline Cancer & Association between FBXW7 loss-of-function and patient clinical outcomes \\
\hline B-ALL & Pediatric B-ALL: FBXW7 is inversely correlated with disease progression. \\
T-ALL & Overall, FBXW7 is important in disease survival and is linked to specific drug/chemotherapy regime in T-ALL. \\
& Mutation(s) in FBXW7 are not associated with treatment outcomes in newly diagnosed adult T-ALL (UKALLXII/ \\
& ECOG E2993 regime) or pediatric T-ALL. However, mutation(s) in FBXW7 are linked to better overall survival and \\
& event-free survival in LALA-94 and GRAALL-2003 treatment groups. \\
& Activating mutations in Notch (Notch or FBXW7) in pediatric T-ALL lead to better overall response to chemother- \\
& apy, but overall patient outcomes differ. \\
& FBXW7 mutation(s) do not correlate with 5 year overall survival or disease-free survival in CRC; however, distinct \\
& mutations had better overall survival than others. \\
& In metastatic CRC patients (mCRC) missense mutation(s) or loss of FBXW7, demonstrate shorter overall survival \\
Colorectal Cancer (CRC) & and drug resistance to Oxaliplatin, respectively. \\
& FBXW7 mutation(s) show resistance to anti-epidermal growth factor receptor (EGFR) immunotherapy treatment \\
& (ie. Cetuximab or Panitumumab).
\end{tabular}

Esophageal and Gastric Cancers (ESCC)

Hepatocellular Carcinoma (HCC) and intrahepatic cholangiocarcinoma (IHCC)

Non-small cell lung cancer (NSCLC)

Ovarian Carcinoma

Glioblastoma

Breast Cancer

Pancreatic Cancer
FBXW7 is associated with muscle-invasive tumor cases (T2-4), lymphatic-invasive tumor cases, and stage II-IV cases.

Copy number loss of FBXW7 is associated with poorer clinical outcome; while Loss of FBXW7 protein expression is correlated with poor prognosis and adjuvant chemotherapy response.

Aberrant FBXW7 mRNA expression is correlated with lymph node metastasis and tumor stage III-IV.

Reduced FBXW7 expression is correlated with lymph node metastasis, tumor size, and poor prognosis in primary gastric cancer.

Lower FBXW7 in ESCC tissue show poorer overall survival and lower 5-year survival.

Targeting of FBXW7 can lead to Cisplatin resistance in human gastric cancer cells.

Lower FBXW7 expression correlates in HCC patients with higher histological grade and advanced tumor-nodemetastasis.

In HCC patients, FBXW7 correlates with tumor differentiation, the incidence of portal or hepatic venous invasion, metastasis, and poorer clinical pathologic features (including large tumor size, high pathological grading, and advanced TNM stage).

Low expression of FBXW7 in both tumor and non-tumor tissue is an independent risk factor for HCC recurrence in patients after hepatectomy.

Reduced FBXW7 expression correlates with tumor progression and poor prognosis in IHCC.

Lower FBXW7 expression is associated with more aggressive cancer and shorter survival time in NSCLC.

FBXW7 down-regulation is associated with EGFR inhibitor-resistance in NSCLC.

Lower FBXW7 expression in ovarian carcinomas, compared to borderline or benign tumors.

FBXW7 expression levels were lowest in serious carcinomas, followed by endometrioid carcinomas, clear cell carcinomas, and mucinous carcinomas.

Lower FBXW7 expression in patients with grade IV glioma.

FBXW7 serves as a prognostic marker in glioblastoma; with levels of FBXW7 correlating with survival.

FBXW7 expression is inversely correlated with glioma histology and positively correlated with patient survival time.

Higher FBXW7 gene expression correlates with increased disease-free survival in breast cancer patients, especially ER negative and basal subtypes.

Higher FBXW7 expression was associated with increased overall survival in patients with ER negative, ERBB2, and basal subtype tumors.

Higher FBXW7 expression was associated with decreased overall survival in patients with normal-like subtype.

Overall, FBXW7 $\beta$ methylation is associated with favorable prognosis and poorly differentiated tumors in breast cancer.

Low expression of FBXW7 is an independent poor prognostic factor for pancreatic cancer; low FBXW7 correlated with overall, cancer-specific, and relapse-free survival rates.

Levels of FBXW7 expression are associated with sensitivity to gemcitabine treatment. 


\section{Conclusions}

FBXW7 is an essential tumor suppressor and is frequently inactivated in human cancer cells (Table 3). This may offer opportunities to selectively target FBXW7 mutant cells through synthetic-lethal methods or oncogene dependence. This is possible by targeting genes that are selectively essential in cell lines carrying particular driver mutations, but not normal cells with wild-type FBXW7. In support of this model, human breast cancer cells with loss of FBXW7 are hypersensitive to rapamycin [50]. Therefore, inactivation of FBXW7 can be targeted by an mTOR inhibitor to reverse the oncogenic effect of an FBXW7 mutation [50]. As another example, FBXW7 has been demonstrated to target GR $\alpha$ in T-ALL. Reduced FBXW7 expression or function increased the glucocorticoid sensitivity in T-ALL, but not the sensitivity to other chemotherapy drugs [112]. Thus, glucocorticoid treatment can provide a therapeutic window to selectively block FBXW7 mutant cells and spare normal FBXW7 wild-type cells. In addition, down-regulation of GSK3 $\beta$ reduces c-Myc T58 phosphorylation, which impairs FBXW7-mediated c-Myc degradation. The accumulation of c-Myc increases the expression of TRAIL5 (TNF-related apoptosis-inducing ligand death receptor 5), which increases TRAILR5 (death receptor 5)-induced apoptosis both in vitro and in vivo [155]. This may be used to target c-Myc-overexpressing cells in FBXW7-deficient cell lines. Similarly, the histone deacetylase (HDAC) inhibitor Vorinostat induces apoptosis through down-regulation of $\mathrm{Mcl}-1$ and up-regulation of the pro-apoptotic proteins Noxa (PMA-Induced Protein 1) and Bim (BCL2 Like 11) [49]. Mutation of FBXW7 in squamous cell carcinoma (SCC) increases Mcl-1and Bim expression, which leads to resistance to standard chemotherapy but increases susceptibility to HDAC inhibitors [49]. When combining HDAC inhibitors with BH3-mimetic ABT-737, cancer cells show hypersensitivity to the treatment [49]. Finally, human colorectal cells deficient in FBXW7 are dependent on spindle assembly checkpoint proteins BUBR1, BUB1, and MPS1 [156]. Reducing BUBR1 in cells lacking FBXW7 leads to cell aneuploidy and up-regulation of p53 expression [156]. While most studies focus on the cell-autonomous function of FBXW7 in tumor cells, it has also been shown that FBXW7 affects the tumor microenvironment and inhibits tumor metastasis [157]. Specifically, knockout of FBXW7 in mouse bone marrow-derived stromal cells increases Notch expression and then activates chemokine CCL2 (C-C motif chemokine ligand 2) expression [157]. Increased CCL2 in serum recruits both monocytic myeloid-derived suppressor cells and macrophages to the tumor site, thereby increasing tumor metastasis [157]. Importantly, the effect of FBXW7 depletion can be reversed by a CCL2 receptor antagonist, which provides a therapeutic strategy to target FBXW7-deficient cells in clinics [157].

Although a lot of progress has been made regarding the regulation and function of the tumor suppressor FBXW7 in normal and tumoral cells, many questions still remain open-ended. For instance, the possibility that mutated forms of FBXW7 have oncogenic effects offers an opportunity for targeted therapies. Along these lines, recent studies suggest that, unlike the hot spot arginine mutations (R465, R479 and R505), some mutations may differentially affect degradation of some FBXW7 targets. A better understanding of the conformational changes responsible for these phenotypes may also allow for the design of small inhibitors that selectively affect specific downstream signaling pathways and/or to alter FBXW7 substrate selection. Since FBXW7 mutations are frequently heterozygote, it is also important to understand the contribution of FBXW7 monomers as well as dimers within a both mutated or a single mutated unit.

\section{Abbreviations}

ALL: Acute lymphoblastic leukemia; AML: Acute myelogenous leukemia; APC/ C: Anaphase Promoting Complex/Cyclosome; API-1: AKT inhibitor; ATL: Adult T-cell leukemia; ATM: ATM Serine/Threonine Kinase; AURKA: Aurora kinase A; B-ALL: B-cell acute lymphoblastic leukemia; Bim: BCL2 Like 11; CCL2: C-C motif chemokine ligand 2; CCLE: Cancer Cell Line Encyclopedia;

CML: Chronic myelogenous leukemia; COAD: Colorectal adenocarcinoma; COSMIC: Catalogue of Somatic Mutations in Cancer; CPD: CDC4

phosphodegron; CRC: Colorectal cancer; Cul-1: Cullin/Cdc53; cyclin E/ CDK2: Cyclin E/cyclin-dependent kinase Cdk2; DNMT1: DNA methyltransferase 1; DSBs: Double DNA strand breaks; EBP1: ErbB3 receptorbinding protein; EBP2: EBNA1-binding protein 2; EGFR: Epidermal growth factor receptor; EOGC: Early-onset gastric cancers; ERBB2: Erb-B2 Receptor Tyrosine Kinase 2; ERK: Extracellular signal-regulated kinase; ESCC: Esophageal squamous cell carcinoma; EZH2: Enhancer of zeste homolog 2 polycomb repressive complex 2; FAM83D: Family with sequence similarity 83, member D; FBXW7: F-box and WD repeat domain containing 7; Glmn: Glomulin; GRAALL-2003: Group for Research on Adult Acute Lymphoblastic Leukemia2003 trials; GRa: Glucocorticoid receptor alpha; GSK3ß: Glycogen synthase kinase 3 beta; HCC: Hepatocellular carcinoma; HDAC: Histone deacetylase; HIF-1a: Hypoxia inducible factor-1; HTLV-I: Human T-cell leukemia virus; IHCC: Intrahepatic cholangiocarcinoma; ILK: Integrin-linked kinase; JNKs: Jun $\mathrm{N}$-terminal kinases; KRAS: Kirsten Rat Sarcoma Viral Proto-Oncogene; KSHV: Kaposi's sarcoma-associated herpesvirus; LALA-94: Lymphoblastic Acute Leukemia in Adults-94 trials; LIC: Leukemia-initiating cell; IncRNA: long non-coding RNA; LOH: Loss of heterozygosity; LSD: LT-stabilization domain; MAPK: Mitogen-activated protein kinase; MCl-1: Myeloid cell leukemia-1; MCV: Merkel cell polyomavirus; miRNA: microRNA; mTOR2: mTOR complex 2; NHEJ: Non-homologous end joining; NICD: Notch nuclear intracellular domain; NLS: Nuclear localization signals; Notch: Notch (Drosophila) Homolog 1 Translocation-Associated); Noxa: PMA-Induced Protein 1; NPM: Nucleophosmin; NSCLC: Non-small cell lung cancer;

PIKK: Phosphoinositide 3-kinase-related kinase; Pin1: Peptidyl-prolyl cis-trans isomerase NIMA-interacting 1; PKC: Protein Kinase C; PIk2: Polo-like kinase 2; PS: Presenilin; PTEN: Phosphatase and tensin homologue deleted on chromosome 10; Rack1: Receptor for activated C-kinase 1; RCC: Renal cell carcinoma; RICTOR: Rapamycin-insensitive companion of mammalian target of rapamycin; SAC: Spindle assembly checkpoint; SCC: Squamous cell carcinoma; SCF/ß-TrCP: Skp1-Cdc53/Cullin-F-box-protein complex; SMAD4: Mothers Against DPP Homolog 4; SNCA: Alpha-synuclein; TAL1/ SCL: Squamous cell carcinoma; TOP2A: DNA topoisomerase II; TRAIL5: TNFrelated apoptosis-inducing ligand death receptor 5; UbcH5: Ubiquitin Conjugating Enzyme E2 D1; UPS: Ubiquitin-proteasome system; USP: Ubiquitin-specific proteases; VEGF-A: Vascular endothelial growth factor A; WD40: Tryptophan-aspartic acid motif; XRCC4: DNA repair protein X-Ray Repair Cross Complementing 4 


\section{Acknowledgements}

The authors would like to thank Brandi Miller for editorial assistance.

\section{Funding}

This work was supported by grant R01CA201309 to Christophe Nicot.

\section{Authors' contributions}

$\mathrm{MB}, \mathrm{CHY}$ and $\mathrm{CN}$ designed and drafted the manuscript. All authors read and approved the final manuscript.

\section{Ethics approval and consent to participate}

Not applicable.

\section{Consent for publication}

Not applicable.

\section{Competing interests}

The authors declare that they have no competing interests.

\section{Publisher's Note}

Springer Nature remains neutral with regard to jurisdictional claims in published maps and institutional affiliations.

\section{Received: 15 March 2018 Accepted: 16 July 2018}

Published online: 07 August 2018

\section{References}

1. Welcker M, Orian A, Grim JE, Eisenman RN, Clurman BE. A nucleolar isoform of the Fbw7 ubiquitin ligase regulates c-Myc and cell size. Curr Biol. 2004;14:1852-7.

2. Koepp DM, Schaefer LK, Ye X, Keyomarsi K, Chu C, Harper JW, Elledge SJ. Phosphorylation-dependent ubiquitination of cyclin E by the SCFFbw7 ubiquitin ligase. Science. 2001;294:173-7.

3. Nash P, Tang X, Orlicky S, Chen Q, Gertler FB, Mendenhall MD, Sicheri F, Pawson T, Tyers M. Multisite phosphorylation of a CDK inhibitor sets a threshold for the onset of DNA replication. Nature. 2001:414:514-21.

4. Welcker M, Singer J, Loeb KR, Grim J, Bloecher A, Gurien-West M, Clurman $\mathrm{BE}$, Roberts JM. Multisite phosphorylation by Cdk2 and GSK3 controls cyclin E degradation. Mol Cell. 2003;12:381-92.

5. Akhoondi S, Sun D, von der Lehr N, Apostolidou S, Klotz K, Maljukova A, Cepeda D, Fiegl H, Dafou D, Marth C, Mueller-Holzner E, Corcoran M, Dagnell M, Nejad SZ, Nayer BN, Zali MR, Hansson J, Egyhazi S, Petersson F, Sangfelt P, Nordgren H, Grander D, Reed SI, Widschwendter M, Sangfelt O, Spruck C. FBXW7/hCDC4 is a general tumor suppressor in human cancer. Cancer Res. 2007:67:9006-12.

6. Grim JE, Knoblaugh SE, Guthrie KA, Hagar A, Swanger J, Hespelt J, Delrow JJ, Small T, Grady WM, Nakayama KI, Clurman BE. Fbw7 and p53 cooperatively suppress advanced and chromosomally unstable intestinal cancer. Mol Cell Biol. 2012:32:2160-7.

7. Matsuoka S, Oike Y, Onoyama I, Iwama A, Arai F, Takubo K, Mashimo Y, Oguro H, Nitta E, Ito K, Miyamoto K, Yoshiwara H, Hosokawa K, Nakamura Y, Gomei Y, Iwasaki H, Hayashi Y, Matsuzaki Y, Nakayama K, Ikeda Y, Hata A, Chiba S, Nakayama KI, Suda T. Fbxw7 acts as a critical fail-safe against premature loss of hematopoietic stem cells and development of T-ALL. Genes Dev. 2008;22:986-91.

8. Sancho R, Jandke A, Davis H, Diefenbacher ME, Tomlinson I, Behrens A. F-box and WD repeat domain-containing 7 regulates intestinal cell lineage commitment and is a haploinsufficient tumor suppressor. Gastroenterology. 2010;139:929-41.

9. Takada M, Zhang W, Suzuki A, Kuroda TS, Yu Z, Inuzuka H, Gao D, Wan L, Zhuang M, Hu L, Zhai B, Fry CJ, Bloom K, Li G, Karpen GH, Wei W, Zhang Q. FBW7 Loss Promotes Chromosomal Instability and Tumorigenesis via Cyclin E1/CDK2-Mediated Phosphorylation of CENP-A. Cancer Res. 2017;77:4881-93.

10. Arabi A, Ullah K, Branca RM, Johansson J, Bandarra D, Haneklaus M, Fu J, Aries I, Nilsson P, Den Boer ML, Pokrovskaja K, Grander D, Xiao G, Rocha S, Lehtio J, Sangfelt O. Proteomic screen reveals Fbw7 as a modulator of the NF-kappaB pathway. Nat Commun. 2012;3:976.

11. Davis RJ, Welcker M, Clurman BE. Tumor suppression by the Fbw7 ubiquitin ligase: mechanisms and opportunities. Cancer Cell. 2014;26:455-64.

12. Welcker M, Orian A, Jin J, Grim JE, Harper JW, Eisenman RN, Clurman BE. The Fbw7 tumor suppressor regulates glycogen synthase kinase 3 phosphorylation-dependent c-Myc protein degradation. Proc Natl Acad Sci U S A. 2004;101:9085-90.
13. Fernandez PC, Frank SR, Wang L, Schroeder M, Liu S, Greene J, Cocito A, Amati B. Genomic targets of the human c-Myc protein. Genes Dev. 2003;17: $1115-29$.

14. Kress TR, Sabo A, Amati B. MYC: connecting selective transcriptional control to global RNA production. Nat Rev. Cancer. 2015;15:593-607.

15. Yada M, Hatakeyama S, Kamura T, Nishiyama M, Tsunematsu R, Imaki H, Ishida N, Okumura F, Nakayama K, Nakayama KI. Phosphorylation-dependent degradation of c-Myc is mediated by the F-box protein Fbw7. EMBO J. 2004:23:2116-25.

16. King B, Trimarchi T, Reavie L, Xu L, Mullenders J, Ntziachristos P, ArandaOrgilles B, Perez-Garcia A, Shi J, Vakoc C, Sandy P, Shen SS, Ferrando A, Aifantis I. The ubiquitin ligase FBXW7 modulates leukemia-initiating cell activity by regulating MYC stability. Cell. 2013;153:1552-66.

17. Reavie L, Buckley SM, Loizou E, Takeishi S, Aranda-Orgilles B, Ndiaye-Lobry D, Abdel-Wahab O, Ibrahim S, Nakayama Kl, Aifantis I. Regulation of c-Myc Ubiquitination Controls Chronic Myelogenous Leukemia Initiation and Progression. Cancer Cell. 2013;23:362-75.

18. Bahram F, von der Lehr N, Cetinkaya C, Larsson LG. c-Myc hot spot mutations in lymphomas result in inefficient ubiquitination and decreased proteasome-mediated turnover. Blood. 2000;95:2104-10.

19. Popov N, Schulein C, Jaenicke LA, Eilers M. Ubiquitylation of the amino terminus of Myc by SCF(beta-TrCP) antagonizes SCF(Fbw7)-mediated turnover. Nat Cell Biol. 2010;12:973-81.

20. Popov N, Herold S, Llamazares M, Schulein C, Eilers M. Fbw7 and Usp28 regulate myc protein stability in response to DNA damage. Cell Cycle. 2007; 6:2327-31.

21. Sun $X X$, He X, Yin L, Komada M, Sears RC, Dai MS. The nucleolar ubiquitinspecific protease USP36 deubiquitinates and stabilizes c-Myc. Proc Natl Acad Sci U S A. 2015;112:3734-9.

22. Grim JE, Gustafson MP, Hirata RK, Hagar AC, Swanger J, Welcker M, Hwang HC, Ericsson J, Russell DW, Clurman BE. Isoform- and cell cycle-dependent substrate degradation by the Fbw7 ubiquitin ligase. J Cell Biol. 2008;181: 913-20.

23. Strohmaier H, Spruck CH, Kaiser P, Won KA, Sangfelt O, Reed SI. Human Fbox protein $\mathrm{hCdc} 4$ targets cyclin $\mathrm{E}$ for proteolysis and is mutated in a breast cancer cell line. Nature. 2001;413:316-22.

24. Minella AC, Grim JE, Welcker M, Clurman BE. p53 and SCFFbw7 cooperatively restrain cyclin E-associated genome instability. Oncogene. 2007;26:6948-53.

25. Moore JD. In the wrong place at the wrong time: does cyclin mislocalization drive oncogenic transformation? Nat Rev. Cancer. 2013; https://doi.org/10.1038/nrc3468.

26. Rajagopalan H, Jallepalli PV, Rago C, Velculescu VE, Kinzler KW, Vogelstein B, Lengauer C. Inactivation of hCDC4 can cause chromosomal instability. Nature. 2004;428:77-81.

27. Hubalek MM, Widschwendter A, Erdel M, Gschwendtner A, Fiegl HM, Muller HM, Goebel G, Mueller-Holzner E, Marth C, Spruck CH, Reed SI, Widschwendter M. Cyclin E dysregulation and chromosomal instability in endometrial cancer. Oncogene. 2004;23:4187-92.

28. Tetzlaff MT, Yu W, Li M, Zhang P, Finegold M, Mahon K, Harper JW, Schwartz RJ, Elledge SJ. Defective cardiovascular development and elevated cyclin E and Notch proteins in mice lacking the Fbw7 F-box protein. Proc Natl Acad Sci U S A. 2004;101:3338-45.

29. Davis RJ, Swanger J, Hughes BT, Clurman BE. The PP2A-B56 Phosphatase Opposes Cyclin E Autocatalytic Degradation via Site-Specific Dephosphorylation. Mol Cell Biol. 2017;37(8).

30. Tan Y, Sun D, Jiang W, Klotz-Noack K, Vashisht AA, Wohlschlegel J, Widschwendter M, Spruck C. PP2A-B55beta antagonizes cyclin E1 proteolysis and promotes its dysregulation in cancer. Cancer Res. 2014;74: 2006-14.

31. Minella AC, Welcker M, Clurman BE. Ras activity regulates cyclin E degradation by the Fbw7 pathway. Proc Natl Acad Sci U S A. 2005;102:9649-54.

32. Hori K, Sen A, Artavanis-Tsakonas S. Notch signaling at a glance. J Cell Sci. 2013;126:2135-40

33. Pancewicz J, Nicot C. Current views on the role of Notch signaling and the pathogenesis of human leukemia. BMC Cancer. 2011;11:502.

34. Louvi A, Artavanis-Tsakonas S. Notch and disease: a growing field. Semin Cell Dev Biol. 2012;23:473-80

35. Fryer $\mathrm{CJ}$, White JB, Jones KA. Mastermind recruits CycC:CDK8 to phosphorylate the Notch ICD and coordinate activation with turnover. Mol Cell. 2004;16:509-20. 
36. Li N, Fassl A, Chick J, Inuzuka H, Li X, Mansour MR, Liu L, Wang H, King B, Shaik S, Gutierrez A, Ordureau A, Otto T, Kreslavsky T, Baitsch L, Bury L, Meyer CA, Ke N, Mulry KA, Kluk MJ, Roy M, Kim S, Zhang X, Geng Y, Zagozdzon A, Jenkinson S, Gale RE, Linch DC, Zhao JJ, Mullighan CG, Harper JW, Aster JC, Aifantis I, von Boehmer H, Gygi SP, Wei W, Look AT, Sicinski P. Cyclin C is a haploinsufficient tumour suppressor. Nat Cell Biol. 2014;16:1080-91.

37. Foltz DR, Santiago MC, Berechid BE, Nye JS. Glycogen synthase kinase-3beta modulates notch signaling and stability. Curr Biol. 2002;12:1006-11.

38. Jin YH, Kim H, Oh M, Ki H, Kim K. Regulation of Notch1/NICD and Hes1 expressions by GSK-3alpha/beta. Mol Cells. 2009;27:15-9.

39. Mo JS, Kim MY, Han SO, Kim IS, Ann EJ, Lee KS, Seo MS, Kim JY, Lee SC, Park JW, Choi EJ, Seong JY, Joe CO, Faessler R, Park HS. Integrin-linked kinase controls Notch1 signaling by down-regulation of protein stability through Fbw7 ubiquitin ligase. Mol Cell Biol. 2007;27:5565-74.

40. Ntziachristos P, Lim JS, Sage J, Aifantis I. From Fly Wings to Targeted Cancer Therapies: A Centennial for Notch Signaling. Cancer Cell. 2014;25:318-34.

41. Weng AP, Ferrando AA, Lee W, Morris JP, Silverman LB, Sanchez-lrizarry C, Blacklow SC, Look AT, Aster JC. Activating mutations of NOTCH1 in human T cell acute lymphoblastic leukemia. Science. 2004;306:269-71.

42. Malyukova A, Dohda T, von der Lehr N, Akhoondi S, Corcoran M, Heyman M, Spruck C, Grander D, Lendahl U, Sangfelt O. The tumor suppressor gene hCDC4 is frequently mutated in human T-cell acute lymphoblastic leukemia with functional consequences for Notch signaling. Cancer Res. 2007;67:5611-6.

43. O’Neil J, Grim J, Strack P, Rao S, Tibbitts D, Winter C, Hardwick J, Welcker M, Meijerink JP, Pieters R, Draetta G, Sears R, Clurman BE, Look AT. FBW7 mutations in leukemic cells mediate NOTCH pathway activation and resistance to gamma-secretase inhibitors. J Exp Med. 2007;204:1813-24.

44. Michels J, O'Neill JW, Dallman CL, Mouzakiti A, Habens F, Brimmell M, Zhang KY, Craig RW, Marcusson EG, Johnson PW, Packham G. Mcl-1 is required for Akata6 B-lymphoma cell survival and is converted to a cell death molecule by efficient caspase-mediated cleavage. Oncogene. 2004;23:4818-27.

45. Belmar J, Fesik SW. Small molecule Mcl-1 inhibitors for the treatment of cancer. Pharmacol Ther. 2015;145:76-84

46. Ren H, Koo J, Guan B, Yue P, Deng X, Chen M, Khuri FR, Sun SY. The E3 ubiquitin ligases beta-TrCP and FBXW7 cooperatively mediates GSK3dependent $\mathrm{MCl}-1$ degradation induced by the Akt inhibitor API-1, resulting in apoptosis. Mol Cancer. 2013;12:146.

47. Inuzuka H, Shaik S, Onoyama I, Gao D, Tseng A, Maser RS, Zhai B, Wan L, Gutierrez A, Lau AW, Xiao Y, Christie AL, Aster J, Settleman J, Gygi SP, Kung AL, Look T, Nakayama KI, DePinho RA, Wei W. SCF(FBW7) regulates cellular apoptosis by targeting MCL1 for ubiquitylation and destruction. Nature. 2011;471:104-9.

48. Koo J, Yue P, Deng X, Khuri FR, Sun SY. mTOR Complex 2 Stabilizes Mcl-1 Protein by Suppressing Its Glycogen Synthase Kinase 3-Dependent and SCFFBXW7-Mediated Degradation. Mol Cell Biol. 2015;35:2344-55.

49. He L, Torres-Lockhart K, Forster N, Ramakrishnan S, Greninger P, Garnett MJ, McDermott U, Rothenberg SM, Benes $\mathrm{CH}$, Ellisen LW. Mcl-1 and FBW7 control a dominant survival pathway underlying HDAC and $\mathrm{BCl}-2$ inhibitor synergy in squamous cell carcinoma. Cancer Discov. 2013;3:324-37.

50. Mao JH, Kim IJ, Wu D, Climent J, Kang HC, DelRosario R, Balmain A. FBXW7 targets $\mathrm{mTOR}$ for degradation and cooperates with PTEN in tumor suppression. Science. 2008;321:1499-502.

51. Koo J, Wu X, Mao Z, Khuri FR, Sun SY. Rictor Undergoes Glycogen Synthase Kinase 3 (GSK3)-dependent, FBXW7-mediated Ubiquitination and Proteasomal Degradation. J Biol Chem. 2015;290:14120-9.

52. Liu Y, Huang $Y$, Wang Z, Li X, Louie A, Wei G, Mao JH. Temporal mTOR inhibition protects Fbxw7-deficient mice from radiation-induced tumor development. Aging (Albany NY). 2013;5:111-9.

53. Wei W, Jin J, Schlisio S, Harper JW, Kaelin WG Jr. The v-Jun point mutation allows c-Jun to escape GSK3-dependent recognition and destruction by the Fbw7 ubiquitin ligase. Cancer Cell. 2005;8:25-33.

54. Babaei-Jadidi R, Li N, Saadeddin A, Spencer-Dene B, Jandke A, Muhammad B, Ibrahim EE, Muraleedharan R, Abuzinadah M, Davis H, Lewis A, Watson S, Behrens A, Tomlinson I, Nateri AS. FBXW7 influences murine intestinal homeostasis and cancer, targeting Notch, Jun, and DEK for degradation. J Exp Med. 2011;208:295-312.

55. Fu Y, Lin Y, Yang Z, Yang G, Li G, Liu Y, Tan X, Huang Y, Wu X, Wang Y, Xiong $H$, Zhang M, Fang L, Ge $Y$, Zeng J, Cai $Y$, Bai J, Wu S. FBXW7 overexpression suppresses renal cancer cell proliferation and induces apoptosis. Med Oncol. 2015;32:215.

56. Otto T, Horn S, Brockmann M, Eilers U, Schuttrumpf L, Popov N, Kenney AM, Schulte $\mathrm{JH}$, Beijersbergen R, Christiansen H, Berwanger B, Eilers M.
Stabilization of N-Myc is a critical function of Aurora A in human neuroblastoma. Cancer Cell. 2009;15:67-78.

57. Mao JH, Perez-Losada J, Wu D, Delrosario R, Tsunematsu R, Nakayama Kl, Brown K, Bryson S, Balmain A. Fbxw7/Cdc4 is a p53-dependent, haploinsufficient tumour suppressor gene. Nature. 2004;432:775-9.

58. Kwon YW, Kim IJ, Wu D, Lu J, Stock WA Jr, Liu Y, Huang Y, Kang HC, DelRosario R, Jen KY, Perez-Losada J, Wei G, Balmain A, Mao JH. Pten regulates Aurora-A and cooperates with Fbxw7 in modulating radiationinduced tumor development. Mol Cancer Res. 2012;10:834-44.

59. Fujii Y, Yada M, Nishiyama M, Kamura T, Takahashi H, Tsunematsu R, Susaki E, Nakagawa T, Matsumoto A, Nakayama Kl. Fbxw7 contributes to tumor suppression by targeting multiple proteins for ubiquitin-dependent degradation. Cancer Sci. 2006;97:729-36.

60. Yeh CH, Bellon M, Pancewicz-Wojtkiewicz J, Nicot C. Oncogenic mutations in the FBXW7 gene of adult T-cell leukemia patients. Proc Natl Acad Sci U S A. 2016;113:6731-6.

61. Rocher-Ros V, Marco S, Mao JH, Gines S, Metzger D, Chambon P, Balmain A, Saura CA. Presenilin modulates EGFR signaling and cell transformation by regulating the ubiquitin ligase Fbw7. Oncogene. 2010;29:2950-61.

62. Zhang Q, Karnak D, Tan M, Lawrence TS, Morgan MA, Sun Y. FBXW7 Facilitates Nonhomologous End-Joining via K63-Linked Polyubiquitylation of XRCC4. Mol Cell. 2016; https://doi.org/10.1016/j.molcel.2015.12.010.

63. Uhlen M, Fagerberg L, Hallstrom BM, Lindskog C, Oksvold P, Mardinoglu A, Sivertsson A, Kampf C, Sjostedt E, Asplund A, Olsson I, Edlund K, Lundberg E, Navani S, Szigyarto CA, Odeberg J, Djureinovic D, Takanen JO, Hober S, Alm T, Edqvist PH, Berling H, Tegel H, Mulder J, Rockberg J, Nilsson P, Schwenk JM, Hamsten M, von Feilitzen K, Forsberg M, Persson L, Johansson F, Zwahlen M, von Heijne G, Nielsen J, Ponten F. Proteomics. Tissue-based map of the human proteome. Science. 2015;347:1260419.

64. Zhang P, Cao L, Fan P, Mei Y, Wu M. LncRNA-MIF, a c-Myc-activated long non-coding RNA, suppresses glycolysis by promoting Fbxw7-mediated cMyc degradation. EMBO Rep. 2016;17:1204-20.

65. Liu X, Ma J, Xu F, Li L. TINCR suppresses proliferation and invasion through regulating miR-544a/FBXW7 axis in lung cancer. Biomed Pharmacother. 2018;99:9-17.

66. Wang Y, Liu Z, Yao B, Li Q, Wang L, Wang C, Dou C, Xu M, Liu Q, Tu K. Long noncoding RNA CASC2 suppresses epithelial-mesenchymal transition of hepatocellular carcinoma cells through CASC2/miR-367/FBXW7 axis. Mol Cancer. 2017;16:123.

67. Cao S, Wang Y, Li J, Lv M, Niu H, Tian Y. Tumor-suppressive function of long noncoding RNA MALAT1 in glioma cells by suppressing miR-155 expression and activating FBXW7 function. Am J Cancer Res. 2016;6:2561-74.

68. Xu Y, Sengupta T, Kukreja L, Minella AC. MicroRNA-223 regulates cyclin E activity by modulating expression of F-box and WD-40 domain protein 7. J Biol Chem. 2010;285:34439-46.

69. Lerner M, Lundgren J, Akhoondi S, Jahn A, Ng HF, Akbari Moqadam F, Oude Vrielink JA, Agami R, Den Boer ML, Grander D, Sangfelt O. MiRNA-27a controls FBW7/hCDC4-dependent cyclin E degradation and cell cycle progression. Cell Cycle. 2011;10:2172-83.

70. Mavrakis K, Van Der Meulen J, Wolfe AL, Liu X, Mets E, Taghon T, Khan AA, Setty M, Rondou P, Vandenberghe P, Delabesse E, Benoit Y, Socci NB, Leslie CS, Van Vlierberghe P, Speleman F, Wendel HG. A cooperative microRNAtumor suppressor gene network in acute T-cell lymphoblastic leukemia (TALL). Nat Genet. 2011;43:673-8.

71. Li L, Sarver AL, Khatri R, Hajeri PB, Kamenev I, French AJ, Thibodeau SN, Steer CJ, Subramanian S. Sequential expression of miR-182 and miR-503 cooperatively targets FBXW7, contributing to the malignant transformation of colon adenoma to adenocarcinoma. J Pathol. 2014;234:488-501.

72. Xia W, Zhou J, Luo H, Liu Y, Peng C, Zheng W, Ma W. MicroRNA-32 promotes cell proliferation, migration and suppresses apoptosis in breast cancer cells by targeting FBXW7. Cancer Cell Int. 2017;17:14.

73. Tang B, Lei B, Qi G, Liang X, Tang F, Yuan S, Wang Z, Yu S, He S. MicroRNA155-3p promotes hepatocellular carcinoma formation by suppressing FBXW7 expression. J Exp Clin Cancer Res. 2016;35:93.

74. Akhoondi S, Lindstrom L, Widschwendter M, Corcoran M, Bergh J, Spruck C, Grander D, Sangfelt O. Inactivation of FBXW7/hCDC4-beta expression by promoter hypermethylation is associated with favorable prognosis in primary breast cancer. Breast Cancer Res. 2010;12:R105.

75. Kitade S, Onoyama I, Kobayashi H, Yagi H, Yoshida S, Kato M, Tsunematsu R, Asanoma K, Sonoda K, Wake N, Hata K, Nakayama Kl, Kato K. FBXW7 is involved in the acquisition of the malignant phenotype in epithelial ovarian tumors. Cancer Sci. 2016;107:1399-405. 
76. Zhao E, Maj T, Kryczek I, Li W, Wu K, Zhao L, Wei S, Crespo J, Wan S, Vatan L, Szeliga W, Shao I, Wang Y, Liu Y, Varambally S, Chinnaiyan AM, Welling TH, Marquez V, Kotarski J, Wang H, Wang Z, Zhang Y, Liu R, Wang G, Zou W. Cancer mediates effector T cell dysfunction by targeting microRNAs and EZH2 via glycolysis restriction. Nat Immunol. 2015; https://doi.org/10.1038/ni.3313.

77. Jin X, Yang C, Fan P, Xiao J, Zhang W, Zhan S, Liu T, Wang D, Wu H. CDK5/ FBW7-dependent ubiquitination and degradation of EZH2 inhibits pancreatic cancer cell migration and invasion. J Biol Chem. 2017;292:6269-80.

78. Forbes SA, Beare D, Boutselakis H, Bamford S, Bindal N, Tate J, Cole CG, Ward S, Dawson E, Ponting L, Stefancsik R, Harsha B, Kok CY, Jia M, Jubb H, Sondka Z, Thompson S, De T, Campbell PJ. COSMIC: somatic cancer genetics at high-resolution. Nucleic Acids Res. 2017:45:D777-d783.

79. Thompson BJ, Buonamici S, Sulis ML, Palomero T, Vilimas T, Basso G, Ferrando A, Aifantis I. The SCFFBW7 ubiquitin ligase complex as a tumor suppressor in T cell leukemia. J Exp Med. 2007;204:1825-35.

80. Welcker M, Larimore EA, Swanger J, Bengoechea-Alonso MT, Grim JE, Ericsson J, Zheng N, Clurman BE. Fbw7 dimerization determines the specificity and robustness of substrate degradation. Genes Dev. 2013;27:2531-6.

81. Welcker M, Clurman BE. FBW7 ubiquitin ligase: a tumour suppressor at the crossroads of cell division, growth and differentiation. Nat Rev. Cancer. 2008; 8:83-93.

82. Janku F, Wheler JJ, Naing A, Falchook GS, Hong DS, Stepanek VM, Fu S, Piha-Paul SA, Lee JJ, Luthra R, Tsimberidou AM, Kurzrock R. PIK3CA mutation H1047R is associated with response to PI3K/AKT/mTOR signaling pathway inhibitors in early-phase clinical trials. Cancer Res. 2013;73:276-84.

83. Gazdar AF. Activating and resistance mutations of EGFR in non-small-cell lung cancer: role in clinical response to EGFR tyrosine kinase inhibitors. Oncogene. 2009;28(Suppl 1):S24-31.

84. Bonetti P, Davoli T, Sironi C, Amati B, Pelicci PG, Colombo E. Nucleophosmin and its AML-associated mutant regulate c-Myc turnover through Fbw7 gamma. J Cell Biol. 2008;182:19-26.

85. Durgan J, Parker PJ. Regulation of the tumour suppressor Fbw7alpha by PKC-dependent phosphorylation and cancer-associated mutations. Biochem J. 2010;432:77-87.

86. Wang Y, Zhang P, Wang Y, Zhan P, Liu C, Mao JH, Wei G. Distinct Interactions of EBP1 Isoforms with FBXW7 Elicits Different Functions in Cancer. Cancer Res. 2017;77:1983-96.

87. Welcker M, Larimore EA, Frappier L, Clurman BE. Nucleolar targeting of the fbw7 ubiquitin ligase by a pseudosubstrate and glycogen synthase kinase 3 . Mol Cell Biol. 2011;31:1214-24.

88. Welcker M, Clurman BE. The SV40 large T antigen contains a decoy phosphodegron that mediates its interactions with Fbw7/hCdc4. J Biol Chem. 2005;280:7654-8.

89. Min SH, Lau AW, Lee TH, Inuzuka H, Wei S, Huang P, Shaik S, Lee DY, Finn G, Balastik M, Chen CH, Luo M, Tron AE, Decaprio JA, Zhou XZ, Wei W, Lu KP. Negative regulation of the stability and tumor suppressor function of Fbw7 by the Pin1 prolyl isomerase. Mol Cell. 2012;46:771-83.

90. Zheng $M, X u H$, Liao XH, Chen CP, Zhang AL, Lu W, Wang L, Yang D, Wang J, Liu H, Zhou XZ, Lu KP. Inhibition of the prolyl isomerase Pin1 enhances the ability of sorafenib to induce cell death and inhibit tumor growth in hepatocellular carcinoma. Oncotarget. 2017;8:29771-84.

91. Ji S, Qin Y, Shi S, Liu X, Hu H, Zhou H, Gao J, Zhang B, Xu W, Liu J, Liang D, Liu L, Liu C, Long J, Zhou H, Chiao PJ, Xu J, Ni Q, Gao D, Yu X. ERK kinase phosphorylates and destabilizes the tumor suppressor FBW7 in pancreatic cancer. Cell Res. 2015;25:561-73.

92. Cizmecioglu O, Krause A, Bahtz R, Ehret L, Malek N, Hoffmann I. Plk2 regulates centriole duplication through phosphorylation-mediated degradation of Fbxw7 (human Cdc4). J Cell Sci. 2012;125:981-92.

93. Ou B, Zhao J, Guan S, Wangpu X, Zhu C, Zong Y, Ma J, Sun J, Zheng $M$, Feng $H$, Lu A. Plk2 promotes tumor growth and inhibits apoptosis by targeting Fbxw7/Cyclin E in colorectal cancer. Cancer Lett. 2016;380: 457-66.

94. Chen J, Shin JH, Zhao R, Phan L, Wang H, Xue Y, Post SM, Ho Choi H, Chen JS, Wang E, Zhou Z, Tseng C, Gully C, Velazquez-Torres G, Fuentes-Mattei E, Yeung G, Qiao Y, Chou PC, Su CH, Hsieh YC, Hsu SL, Ohshiro K, Shaikenov T, Wang $\mathrm{H}$, Yeung SC, Lee MH. CSN6 drives carcinogenesis by positively regulating Myc stability. Nat Commun. 2014;5:5384.

95. Tron AE, Arai T, Duda DM, Kuwabara H, Olszewski JL, Fujiwara Y, Bahamon BN, Signoretti S, Schulman BA, DeCaprio JA. The glomuvenous malformation protein Glomulin binds Rbx1 and regulates cullin RING ligasemediated turnover of Fbw7. Mol Cell. 2012;46:67-78.
96. Chatr-Aryamontri A, Oughtred R, Boucher L, Rust J, Chang C, Kolas NK, O'Donnell L, Oster S, Theesfeld C, Sellam A, Stark C, Breitkreutz BJ, Dolinski K, Tyers M. The BioGRID interaction database: 2017 update. Nucleic Acids Res. 2017;45:D369-d379.

97. Wang Z, Liu Y, Zhang P, Zhang W, Wang W, Curr K, Wei G, Mao JH. FAM83D promotes cell proliferation and motility by downregulating tumor suppressor gene FBXW7. Oncotarget. 2013;4:2476-86.

98. Mu Y, Zou H, Chen B, Fan Y, Luo S. FAM83D knockdown regulates proliferation, migration and invasion of colorectal cancer through inhibiting FBXW7/Notch-1 signalling pathway. Biomed Pharmacother. 2017;90:548-54.

99. Schulein-Volk C, Wolf E, Zhu J, Xu W, Taranets L, Hellmann A, Janicke LA, Diefenbacher ME, Behrens A, Eilers M, Popov N. Dual regulation of Fbw7 function and oncogenic transformation by Usp28. Cell Rep. 2014;9:1099-109.

100. Hemann MT, Bric A, Teruya-Feldstein J, Herbst A, Nilsson JA, Cordon-Cardo C, Cleveland JL, Tansey WP, Lowe SW. Evasion of the p53 tumour surveillance network by tumour-derived MYC mutants. Nature. 2005;436:807-11.

101. Sears R, Nuckolls F, Haura E, Taya Y, Tamai K, Nevins JR. Multiple Rasdependent phosphorylation pathways regulate Myc protein stability. Genes Dev. 2000;14:2501-14.

102. Yang C, Li S, Wang M, Chang AK, Liu Y, Zhao F, Xiao L, Han L, Wang D, Li S, WU H. PTEN suppresses the oncogenic function of AlB1 through decreasing its protein stability via mechanism involving Fbw7 alpha. Mol Cancer. 2013;12:21.

103. Baek HJ, Yoon JH, Ann EJ, Kim MY, Ahn JS, Kim SH, Jo EH, Lee HJ, Park HS. Alpha-synuclein negatively regulates Notch1 intracellular domain protein stability through promoting interaction with Fbw7. Neurosci Lett. 2015;600:6-11.

104. Lan K, Verma SC, Murakami M, Bajaj B, Kaul R, Robertson ES. Kaposi's sarcoma herpesvirus-encoded latency-associated nuclear antigen stabilizes intracellular activated Notch by targeting the Sel10 protein. Proc Natl Acad Sci U S A. 2007;104:16287-92.

105. Kwun HJ, Shuda M, Feng H, Camacho CJ, Moore PS, Chang Y. Merkel cell polyomavirus small $\mathrm{T}$ antigen controls viral replication and oncoprotein expression by targeting the cellular ubiquitin ligase SCFFbw7. Cell Host Microbe. 2013;14:125-35.

106. Onoyama I, Tsunematsu R, Matsumoto A, Kimura T, de Alboran IM, Nakayama K, Nakayama Kl. Conditional inactivation of Fbxw7 impairs cellcycle exit during T cell differentiation and results in lymphomatogenesis. J Exp Med. 2007;204:2875-88.

107. Kumar V, Palermo R, Talora C, Campese AF, Checquolo S, Bellavia D, Tottone L, Testa G, Miele E, Indraccolo S, Amadori A, Ferretti E, Gulino A, Vacca A, Screpanti I. Notch and NF-kB signaling pathways regulate miR-223/FBXW7 axis in T-cell acute lymphoblastic leukemia. Leukemia. 2014; https://doi.org/10.1038/leu.2014.133.

108. Mansour MR, Sanda T, Lawton LN, Li X, Kreslavsky T, Novina CD, Brand M, Gutierrez A, Kelliher MA, Jamieson CH, von Boehmer H, Young RA, Look AT. The TAL1 complex targets the FBXW7 tumor suppressor by activating miR-223 in human T cell acute lymphoblastic leukemia. J Exp Med. 2013;210:1545-57.

109. Larson Gedman A, Chen Q, Kugel Desmoulin S, Ge Y, LaFiura K, Haska CL, Cherian C, Devidas M, Linda SB, Taub JW, Matherly LH. The impact of NOTCH1, FBW7 and PTEN mutations on prognosis and downstream signaling in pediatric T-cell acute lymphoblastic leukemia: a report from the Children's Oncology Group. Leukemia. 2009;23:1417-25.

110. Mansour MR, Sulis ML, Duke V, Foroni L, Jenkinson S, Koo K, Allen CG, Gale RE, Buck G, Richards S, Paietta E, Rowe JM, Tallman MS, Goldstone AH, Ferrando AA, Linch DC. Prognostic implications of NOTCH1 and FBXW7 mutations in adults with T-cell acute lymphoblastic leukemia treated on the MRC UKALLXII/ECOG E2993 protocol. J Clin Oncol. 2009;27:4352-6.

111. Asnafi V, Buzyn A, Le Noir S, Baleydier F, Simon A, Beldjord K, Reman O, Witz F, Fagot T, Tavernier E, Turlure P, Leguay T, Huguet F, Vernant JP, Daniel F, Bene MC, Ifrah N, Thomas X, Dombret H, Macintyre E. NOTCH1/FBXW7 mutation identifies a large subgroup with favorable outcome in adult T-cell acute lymphoblastic leukemia (T-ALL): a Group for Research on Adult Acute Lymphoblastic Leukemia (GRAALL) study. Blood. 2009;113:3918-24.

112. Malyukova A, Brown S, Papa R, O'Brien R, Giles J, Trahair TN, Pozza LD, Sutton R, Liu T, Haber M, Norris MD, Lock RB, Sangfelt O, Marshall GM. FBXW7 regulates glucocorticoid response in T-cell acute lymphoblastic leukaemia by targeting the glucocorticoid receptor for degradation. Leukemia. 2012; https://doi.org/10.1038/leu.2012.361.

113. Iwatsuki M, Mimori K, Ishii H, Yokobori T, Takatsuno Y, Sato T, Toh H, Onoyama I, Nakayama KI, Baba H, Mori M. Loss of FBXW7, a cell cycle regulating gene, in colorectal cancer: clinical significance. Int J Cancer. 2010; 126:1828-37. 
114. Korphaisarn K, Morris VK, Overman MJ, Fogelman DR, Kee BK, Raghav KPS, Manuel S, Shureiqi I, Wolff RA, Eng C, Menter D, Hamilton SR, Kopetz S, Dasari A. FBXW7 missense mutation: a novel negative prognostic factor in metastatic colorectal adenocarcinoma. Oncotarget. 2017;8:39268-79.

115. Kothari N, Teer JK, Abbott AM, Srikumar T, Zhang Y, Yoder SJ, Brohl AS, Kim $\mathrm{RD}$, Reed DR, Shibata D. Increased incidence of FBXW7 and POLE proofreading domain mutations in young adult colorectal cancers. Cancer. 2016;122:2828-35.

116. Lupini L, Bassi C, Mlcochova J, Musa G, Russo M, VychytilovaFaltejskova P, Svoboda M, Sabbioni S, Nemecek R, Slaby O, Negrini M. Prediction of response to anti-EGFR antibody-based therapies by multigene sequencing in colorectal cancer patients. BMC Cancer. 2015;15:808.

117. Li N, Lorenzi F, Kalakouti E, Normatova M, Babaei-Jadidi R, Tomlinson I, Nateri AS. FBXW7-mutated colorectal cancer cells exhibit aberrant expression of phosphorylated-p53 at serine-15. Oncotarget. 2015;6(11): 9240-56.

118. Kovaleva V, Geissler AL, Lutz L, Fritsch R, Makowiec F, Wiesemann S, Hopt UT, Passlick B, Werner M, Lassmann S. Spatio-temporal mutation profiles of case-matched colorectal carcinomas and their metastases reveal unique de novo mutations in metachronous lung metastases by targeted next generation sequencing. Mol Cancer. 2016;15:63.

119. Braxton DR, Zhang R, Morrissette JD, Loaiza-Bonilla A, Furth EE. Clinicopathogenomic analysis of mismatch repair proficient colorectal adenocarcinoma uncovers novel prognostic subgroups with differing patterns of genetic evolution. Int J Cancer. 2016;139:1546-56.

120. Jardim DL, Wheler JJ, Hess K, Tsimberidou AM, Zinner R, Janku F, Subbiah V, Naing A, Piha-Paul SA, Westin SN, Roy-Chowdhuri S, Meric-Bernstam F, Hong DS. FBXW7 mutations in patients with advanced cancers: clinical and molecular characteristics and outcomes with mTOR inhibitors. PLoS One. 2014;9:e89388.

121. Chang CC, Lin HH, Lin JK, Lin CC, Lan YT, Wang HS, Yang SH, Chen WS, Lin TC, Jiang JK, Chang SC. FBXW7 mutation analysis and its correlation with clinicopathological features and prognosis in colorectal cancer patients. Int J Biol Markers. 2015;30:e88-95.

122. Mouradov D, Domingo E, Gibbs P, Jorissen RN, Li S, Soo PY, Lipton L, Desai J, Danielsen HE, Oukrif D, Novelli M, Yau C, Holmes CC, Jones IT, McLaughlin S, Molloy P, Hawkins NJ, Ward R, Midgely R, Kerr D, Tomlinson IP, Sieber OM. Survival in stage II/II colorectal cancer is independently predicted by chromosomal and microsatellite instability, but not by specific driver mutations. Am J Gastroenterol. 2013;108: 1785-93.

123. Yokobori T, Mimori K, Iwatsuki M, Ishii H, Tanaka F, Sato T, Toh H, Sudo T, Iwaya T, Tanaka Y, Onoyama I, Kuwano H, Nakayama Kl, Mori M. Copy number loss of FBXW7 is related to gene expression and poor prognosis in esophageal squamous cell carcinoma. Int J Oncol. 2012;41: 253-9.

124. Naganawa Y, Ishiguro H, Kuwabara Y, Kimura M, Mitsui A, Katada T, Tanaka T, Shiozaki M, Fujii Y, Takeyama H. Decreased expression of FBXW7 is correlated with poor prognosis in patients with esophageal squamous cell carcinoma. Exp Ther Med. 2010;1:841-6.

125. Milne AN, Leguit R, Corver WE, Morsink FH, Polak M, de Leng WW, Carvalho R, Offerhaus GJ. Loss of CDC4/FBXW7 in gastric carcinoma. Cell Oncol. 2010; 32:347-59.

126. Li MR, Zhu CC, Ling TL, Zhang YQ, Xu J, Zhao EH, Zhao G. FBXW7 expression is associated with prognosis and chemotherapeutic outcome in Chinese patients with gastric adenocarcinoma. BMC Gastroenterol. 2017;17:60.

127. Calcagno DQ, Freitas VM, Leal MF, de Souza CR, Demachki S, Montenegro R, Assumpcao PP, Khayat AS, Smith Mde A, dos Santos AK, Burbano RR. MYC, FBXW7 and TP53 copy number variation and expression in gastric cancer. BMC Gastroenterol. 2013;13:141

128. Yokobori T, Mimori K, Iwatsuki M, Ishii H, Onoyama I, Fukagawa T, Kuwano H, Nakayama Kl, Mori M. p53-Altered FBXW7 expression determines poor prognosis in gastric cancer cases. Cancer Res. 2009;69:3788-94.

129. Zhang Y, Peng Z, Zhao Y, Chen L. microRNA-25 Inhibits Cell Apoptosis of Human Gastric Adenocarcinoma Cell Line AGS via Regulating CCNE1 and MYC. Med Sci Monit. 2016;22:1415-20.

130. Li J, Guo Y, Liang X, Sun M, Wang G, De W, Wu W. MicroRNA-223 functions as an oncogene in human gastric cancer by targeting FBXW7/hCdc4. J Cancer Res Clin Oncol. 2012;138:763-74.
131. Kurashige J, Watanabe M, Iwatsuki M, Kinoshita K, Saito S, Hiyoshi Y, Kamohara H, Baba Y, Mimori K, Baba H. Overexpression of microRNA-223 regulates the ubiquitin ligase FBXW7 in oesophageal squamous cell carcinoma. Br J Cancer. 2012;106:182-8.

132. He D, Huang C, Zhou Q, Liu D, Xiong L, Xiang H, Ma G, Zhang Z. HnRNPK miR-223/FBXW7 feedback cascade promotes pancreatic cancer cell growth and invasion. Oncotarget. 2017;8:20165-78.

133. Zhou X, Jin W, Jia H, Yan J, Zhang G. MiR-223 promotes the cisplatin resistance of human gastric cancer cells via regulating cell cycle by targeting FBXW7. J Exp Clin Cancer Res. 2015;34:28.

134. Imura S, Tovuu LO, Utsunomiya T, Morine $Y$, Ikemoto T, Arakawa $Y$, Kanamoto M, Iwahashi S, Saito Y, Takasu C, Yamada S, Ishikawa D, Bando Y, Shimada M. Role of Fbxw7 expression in hepatocellular carcinoma and adjacent non-tumor liver tissue. J Gastroenterol Hepatol. 2014;29:1822-9.

135. Tu K, Zheng X, Zan X, Han S, Yao Y, Liu Q. Evaluation of Fbxw7 expression and its correlation with the expression of c-Myc, cyclin E and p53 in human hepatocellular carcinoma. Hepatol Res. 2012;42:904-10.

136. Wang X, Zhang J, Zhou L, Sun W, Zheng ZG, Lu P, Gao Y, Yang XS, Zhang ZC, Tao KS, Dou KF. Fbxw7 regulates hepatocellular carcinoma migration and invasion via Notch1 signaling pathway. Int J Oncol. 2015;47:231-43.

137. Tu K, Yang W, Li C, Zheng X, Lu Z, Guo C, Yao Y, Liu Q. Fbxw7 is an independent prognostic marker and induces apoptosis and growth arrest by regulating YAP abundance in hepatocellular carcinoma. Mol Cancer. 2014;13:110.

138. Enkhbold C, Utsunomiya T, Morine Y, Imura S, Ikemoto T, Arakawa Y, Kanamoto M, Iwahashi S, Saito Y, Ishikawa D, Shimada M. Loss of FBXW7 expression is associated with poor prognosis in intrahepatic cholangiocarcinoma. Hepatol Res. 2014;44:E346-52.

139. Sun XF, Sun JP, Hou HT, Li K, Liu X, Ge QX. MicroRNA-27b exerts an oncogenic function by targeting Fbxw7 in human hepatocellular carcinoma. Tumour Biol. 2016:37:15325-32.

140. Yang W, Dou C, Wang Y, Jia Y, Li C, Zheng X, Tu K. MicroRNA-92a contributes to tumor growth of human hepatocellular carcinoma by targeting FBXW7. Oncol Rep. 2015;34:2576-84.

141. Yokobori T, Yokoyama Y, Mogi A, Endoh H, Altan B, Kosaka T, Yamaki E, Yajima T, Tomizawa K, Azuma Y, Onozato R, Miyazaki T, Tanaka S, Kuwano H. FBXW7 mediates chemotherapeutic sensitivity and prognosis in NSCLCs. Mol Cancer Res. 2014;12:32-7.

142. Ye $M$, Zhang $Y$, Zhang $X$, Zhang J, Jing $P$, Cao L, Li N, Li X, Yao L, Zhang J, Zhang J. Targeting FBW7 as a Strategy to Overcome Resistance to Targeted Therapy in Non-Small Cell Lung Cancer. Cancer Res. 2017;77:3527-39.

143. Zhang H, Chen F, He Y, Yi L, Ge C, Shi X, Tang C, Wang D, Wu Y, Nian W. Sensitivity of non-small cell lung cancer to erlotinib is regulated by the Notch/ miR-223/ FBXW7 pathway. Biosci Rep. 2017; https://doi.org/10.1042/bsr20160478.

144. Xiang J, Hang JB, Che JM, Li HC. MiR-25 is up-regulated in non-small cell lung cancer and promotes cell proliferation and motility by targeting FBXW7. Int J Clin Exp Pathol. 2015;8:9147-53.

145. Xu J, Wu W, Wang J, Huang C, Wen W, Zhao F, Xu X, Pan X, Wang W, Zhu $\mathrm{Q}$, Chen L. miR-367 promotes the proliferation and invasion of non-small cell lung cancer via targeting FBXW7. Oncol Rep. 2017;37:1052-8.

146. Li Z, Sun Y, Chen X, Squires J, Nowroozizadeh B, Liang C, Huang J. p53 Mutation Directs AURKA Overexpression via miR-25 and FBXW7 in Prostatic Small Cell Neuroendocrine Carcinoma. Mol Cancer Res. 2015;13:584-91.

147. Li S, Mei Z, Hu HB. 2017.The IncRNA MALAT1 contributes to non-small cell lung cancer development via modulating miR-124/STAT3 axis. J Cell Physiol. https://doi.org/10.1002/jcp.26325

148. Weber DG, Johnen G, Casjens S, Bryk O, Pesch B, Jockel KH, Kollmeier J, Bruning T. Evaluation of long noncoding RNA MALAT1 as a candidate blood-based biomarker for the diagnosis of non-small cell lung cancer. BMC Res Notes. 2013;6:518

149. Wei G, Wang Y, Zhang P, Lu J, Mao JH. Evaluating the prognostic significance of FBXW7 expression level in human breast cancer by a metaanalysis of transcriptional profiles. J Cancer Sci Ther. 2012;4:299-305.

150. Liu Y, Ren S, Castellanos-Martin A, Perez-Losada J, Kwon YW, Huang Y, Wang Z, Abad M, Cruz-Hernandez JJ, Rodriguez CA, Sun Y, Mao JH. Multiple novel alternative splicing forms of FBXW7alpha have a translational modulatory function and show specific alteration in human cancer. PLoS One. 2012;7:e49453.

151. Wang Y, Klijn JG, Zhang Y, Sieuwerts AM, Look MP, Yang F, Talantov D, Timmermans M, Meijer-van Gelder ME, Yu J, Jatkoe T, Berns EM, Atkins D, Foekens JA. Gene-expression profiles to predict distant metastasis of lymphnode-negative primary breast cancer. Lancet. 2005;365:671-9. 
152. Neve RM, Chin K, Fridlyand J, Yeh J, Baehner FL, Fevr T, Clark L, Bayani N, Coppe JP, Tong F, Speed T, Spellman PT, DeVries S, Lapuk A, Wang NJ, Kuo WL, Stilwell JL, Pinkel D, Albertson DG, Waldman FM, McCormick F, Dickson RB, Johnson MD, Lippman M, Ethier S, Gazdar A, Gray JW. A collection of breast cancer cell lines for the study of functionally distinct cancer subtypes. Cancer Cell. 2006;10:515-27.

153. Ibusuki M, Yamamoto Y, Shinriki S, Ando Y, Iwase H. Reduced expression of ubiquitin ligase FBXW7 mRNA is associated with poor prognosis in breast cancer patients. Cancer Sci. 2011;102:439-45.

154. Chiang CH, Chu PY, Hou MF, Hung WC. MiR-182 promotes proliferation and invasion and elevates the HIF-1alpha-VEGF-A axis in breast cancer cells by targeting FBXW7. Am J Cancer Res. 2016;6:1785-98.

155. Rottmann S, Wang Y, Nasoff M, Deveraux QL, Quon KC. A TRAll receptordependent synthetic lethal relationship between MYC activation and GSK3beta/ FBW7 loss of function. Proc Natl Acad Sci U S A. 2005:102:15195-200.

156. Bailey ML, Singh T, Mero P, Moffat J, Hieter P. Dependence of Human Colorectal Cells Lacking the FBW7 Tumor Suppressor on the Spindle Assembly Checkpoint. Genetics. 2015; https://doi.org/10.1534/genetics.115. 180653.

157. Yumimoto K, Akiyoshi S, Ueo H, Sagara Y, Onoyama I, Ohno S, Mori M, Mimori K, Nakayama Kl. F-box protein FBXW7 inhibits cancer metastasis in a non-cell-autonomous manner. J Clin Invest. 2015; https://doi.org/10.1172/ jci78782.

Ready to submit your research? Choose BMC and benefit from:

- fast, convenient online submission

- thorough peer review by experienced researchers in your field

- rapid publication on acceptance

- support for research data, including large and complex data types

- gold Open Access which fosters wider collaboration and increased citations

- maximum visibility for your research: over $100 \mathrm{M}$ website views per year

At BMC, research is always in progress.

Learn more biomedcentral.com/submissions 